Article

\title{
Fragility Analysis of Concrete-Filled Steel Tubular Frame Structures with BRBs under Multiple Earthquakes Considering Strain Rate Effects
}

\author{
Hao Zhang ${ }^{1,2}$, Chao Li $^{3, *}$, Si-Meng Jiang ${ }^{1}$, Peng-Fei Liu ${ }^{3, *}$ and Qing-Meng Gao ${ }^{1}$ \\ 1 School of Civil Engineering, Shenyang Jianzhu University, Shenyang 110168, China; \\ h_zhang@sjzu.edu.cn (H.Z.); 13840151971@163.com (S.-M.J.); 15140348275@163.com (Q.-M.G.) \\ 2 Guangdong Key Laboratory of Earthquake Engineering and Application Technology, Guangzhou University, \\ Guangzhou 510006, China \\ 3 Faculty of infrastructure Engineering, Dalian University of Technology, Dalian 116024, China \\ * Correspondence: chao.li@mail.dlut.edu.cn (C.L.); 31306005@mail.dlut.edu.cn (P.-F.L.)
}

Received: 24 November 2019; Accepted: 19 December 2019; Published: 24 December 2019

check for updates

\begin{abstract}
The fragility of concrete-filled steel tubular (CFST) frame structures with buckling-restrained braces (BRBs) subjected to multiple earthquakes is studied in this paper. First, a fiber beam element model with rate-dependent concrete and steel material properties is developed for CFST members and, then, the effect of the strain rate on the seismic response of the CFST frame structure is investigated numerically. The influence of BRBs on the seismic response of the CFST frame structure is then comparatively analyzed. The seismic responses of the CFST frame structure with BRBs under single mainshocks and earthquake sequences are investigated, and the fragility curves are generated using probabilistic seismic demand analysis. The obtained roof displacement and inter-story drift ratio (ISDR) of the structure decreased by $10.2 \%$ and $6.9 \%$, respectively, when obtained while considering the strain rate effect, compared with those obtained without consideration of the strain rate effect. BRBs can effectively improve the seismic performance of the CFST frame structure in that the maximum roof displacement and ISDR can be reduced by $45.1 \%$ and $43.9 \%$, respectively. Compared with those under single mainshocks, the maximum roof displacement and ISDR of the structure with BRBs under earthquake sequences significantly increase. The fragility of the BRB structure under earthquake sequences is more severe than that under single mainshocks. Therefore, the influences of the strain rate effect and earthquake sequence should be considered to realistically evaluate the seismic fragility of CFST structures.
\end{abstract}

Keywords: CFST frame structure; BRBs; seismic fragility; strain rate effect; earthquake sequences

\section{Introduction}

Earthquakes are among the most destructive natural hazards. In the past few decades, there have been frequent occurrences of earthquake disasters worldwide. The severe damage and collapse of building structures under seismic actions leads to heavy casualties and property losses. Concrete-filled steel tubular (CFST) frame structures installed with energy-dissipating buckling-restrained braces (BRBs) have the advantages of being light weight, high strength, and possessing high lateral stiffness. Thus, they have been widely applied in the seismic design of high-rise and super-high-rise buildings [1-6]. When subjected to an earthquake, BRBs dissipate seismic energy by yielding and reducing the damage to the main structure, which results in good energy dissipation capacity and ductility of the whole structural system. Realistic and reasonable evaluation of the seismic performance of the CFST frame structures with BRBs is of great importance for the seismic design and structural safety of such systems. 
Many studies have shown that both steel and concrete materials are rate dependent. As the loading rate increases, the strength and deformation performance of steel and concrete differ to a certain extent from those under static loading, and the mechanical properties of reinforced concrete (RC) members and structures differ under different loading rates [7-11]. Fu et al. [12], Malvar and Ross [13], and Bischoff and Perry [14] reviewed and summarized the research findings relevant to the concrete strain rate and consistently concluded that the tensile and compressive strengths and elastic modulus of concrete increase with a growing strain rate. Mahin and Bertero [15] along with $\mathrm{Li}$ and $\mathrm{Li}$ [16] experimentally studied the strain rate effect of reinforcing steel under cyclic loading and found that the yield strength of the reinforcing steel increases with an increasing loading rate. Li and Li [17], Wang et al. [18], and Carrillo and Alcoce [19] carried out experimental tests to investigate the dynamic mechanical properties of RC beams, columns, and shear walls. The results showed that the loading rate affects the energy dissipation, stiffness, and strength of RC members to certain extents. Most existing studies have focused on the influence of the loading rate on the mechanical properties of $\mathrm{RC}$ materials and members, yet there are relatively few studies on the effect of strain rate on structure systems under seismic excitations. Asprone et al. [20] studied the impact of the strain rate on the seismic response of RC structures using pushover analysis and incremental dynamic analysis (IDA). It is noted that the calculation results based on static constitutive models are more conservative and it is more reasonable to consider the material strain rate effect. Using the dynamic constitutive model of RC materials, Zhang et al. [21] calculated the nonlinear seismic response of an eccentric RC frame-shear wall structure, which emphasizes the necessity of considering the strain rate effect in structural seismic response analysis.

A vast amount of earthquake damage data has indicated that strong earthquakes are accompanied by multiple foreshocks and aftershocks that occur in the form of earthquake sequences. After being damaged in foreshocks and mainshocks, the damage to the buildings would be further superimposed under the cyclic action of the subsequent aftershocks, which causes the buildings to become more vulnerable. Many researchers have investigated the structural responses under earthquake sequences [22-24]. Fragiacomo et al. [25] studied the seismic response of a steel frame using earthquake sequences as inputs and found that the earthquake sequences significantly increase the displacement ductility demands of the structure. Duerr [26] stated that the influence of earthquake sequences should be considered an important factor in the seismic risk assessment of buildings. Goda and Salami [27] employed different sets of earthquake sequences as inputs for wood frames and performed probabilistic seismic demand analysis (PSDA) using the IDA approach. The results showed that the average dynamic responses of a structure under earthquake sequences increase by $5 \%$ to $20 \%$ compared with those under single mainshocks. Han et al. [28] comparatively analyzed the seismic responses of RC frame structures subjected to actual and synthetic earthquake sequences, which demonstrates that the seismic response of the structure can be severely underestimated if only mainshocks are considered. Using a typical four-story steel frame, Song et al. [29] analyzed the impact of an earthquake sequence on seismic losses. The results showed that the earthquake sequences increase the structural seismic response and economic loss. In previous studies on the impact of earthquake sequences on structural responses, steel structures and RC structures are the major research subjects, yet the seismic performance of the CFST frame structure with BRBs has rarely been investigated.

The application of seismic fragility analysis to the seismic design of buildings can allow an accurate assessment of the seismic performance of building structures, the effective evaluation of the probability of structures reaching different damage limit states under seismic excitation, and a reasonable prediction of the seismic loss of civil engineering structures [30-35]. Li et al. [36] carried out seismic fragility analysis of steel frame structures using different combinations of earthquake sequences. Abdelnaby et al. [37] studied the seismic fragility of an RC frame structure subjected to multiple earthquakes using finite element (FE) analysis. Jeon et al. [38] established a framework for fragility assessments under mainshock-aftershock sequences and conducted fragility analyses on three non-ductile RC frame structures. Li et al. [39] investigated the collapse fragility of steel frame structures 
subjected to mainshock-aftershock sequences. The results from the above studies all indicate that, compared with that under single mainshocks, the seismic fragility of structures under earthquake sequences significantly increases. However, fragility analyses of high-performance structures such as CFST frame structures with BRBs considering both the mainshock-aftershock sequence as an input and the strain rate effect are extremely scarce at present.

In this study, the seismic responses and fragilities of a CFST frame structure with BRBs under earthquake sequences including the strain rate effect were performed using numerical simulation. First, the influences of the strain rate effect and BRBs on the seismic response of the CFST frame structure were investigated. Second, the seismic responses of the CFST frame structure with BRBs under single mainshocks and earthquake sequences were comparatively studied considering the strain rate effect. Lastly, based on a probabilistic seismic demand model (PSDM), the seismic fragility curves of CFST frame structures with BRBs under earthquake sequences were generated. The influence of the amplitude ratios of foreshock (and aftershock) to mainshock of an earthquake sequence on the structural fragility was discussed in detail.

\section{Fiber Beam Element Model of A CFST Member with the Strain Rate Effect}

\subsection{Material Constitutive Models}

\subsubsection{Constitutive Model of Steel}

The bilinear hardening skeleton curve (Figure 1) recommended in the Chinese Code for Design of Concrete Structures GB 50010-2010 [40] is selected as the stress-strain skeleton curve of steel and is shown in the following formula.

$$
\sigma=\left\{\begin{array}{cc}
E s \varepsilon & \varepsilon \leq \varepsilon_{y} \\
f_{y}+k_{1}\left(\varepsilon-\varepsilon_{y}\right) & \varepsilon_{y}<\varepsilon<\varepsilon_{u} \\
0 & \varepsilon \geq \varepsilon_{u}
\end{array}\right.
$$

where $E_{s}$ is Young's modulus of steel, $\varepsilon_{y}$ and $f_{y}$ are the strain and stress at the yielding point, respectively, $\varepsilon_{u}$ is the strain at the ultimate stress, and $k_{1}$ is the slope of the hardening branch.

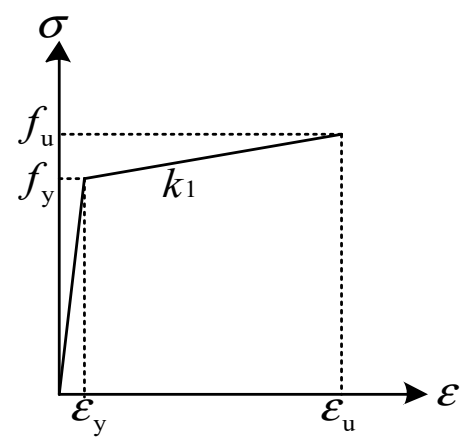

Figure 1. The stress-strain skeleton curve of steel.

The loading and unloading rules of steel proposed by Clough [41] shown in Figure 2 are used, which can effectively consider the stiffness degradation during the loading and unloading process. In this study, the rules are appropriately simplified and corrected to address the numerical stability problem and the inherent deficiency in the model. In particular, the unloading is considered to be an approximately linear elastic process, the corresponding calculation is based on the initial elastic modulus $E_{s}$, and the stress associated with the reverse reloading (shown as (1) and (2) in Figure 2) is calculated using the following equation.

$$
\sigma=E_{Z}\left(\varepsilon-\varepsilon_{a, i}\right)
$$




$$
E_{Z}=\frac{\sigma_{b, i}-\sigma_{a, i}}{\varepsilon_{b, i}-\varepsilon_{a, i}}
$$

where $E_{z}$ is the reloading stiffness, $\sigma_{a, i}$ and $\varepsilon_{a, i}$ are the respective stress and strain at the $i$ th reverse loading point, and $\sigma_{b, i}$ and $\varepsilon_{b, i}$ are the respective maximum stress and strain point in the last loading step. If the steel has never yielded in the reloading direction, the loading path points to the initial yield strain and stress. If the steel has yielded in the reloading direction, the loading path points to the historical maximum strain point.

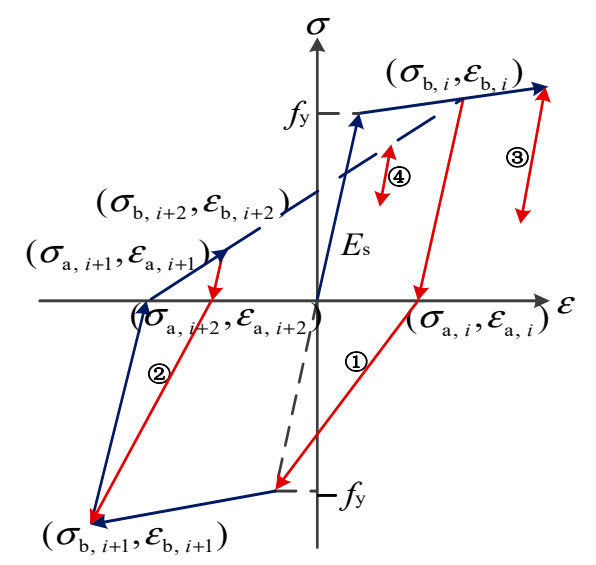

Figure 2. The cyclic constitutive model of steel.

The conditions where reloading occurs after incomplete unloading in the skeleton curve (shown as (3) in Figure 2)-that is, where the strain values at the loading point and the unloading point are very close-should be properly handled. A numerical accuracy issue may lead to an unstable value for the reloading stiffness $E_{z}$. Essentially, $E_{z}$ can be larger than $E_{s}$, which is inconsistent with the actual conditions and is prone to generating program operation errors. In this case, the stress should be approximately calculated using $E_{s}$. As shown in Figure 3, if unloading occurs at point A (using the initial stiffness $E_{s}$ ), then the cyclic loading and unloading occur between two relatively close strains, and the unloading stiffness is higher than the loading stiffness. Thus, the stress value decreases, which does not reflect the actual conditions. Therefore, for incomplete unloading in the reloading curve (4) in Figures 2 and 3), both loading and unloading stresses are calculated using the initial stiffness. After reaching the stress value of the previous unloading point, the loading and unloading stresses are calculated using the actual stiffness.

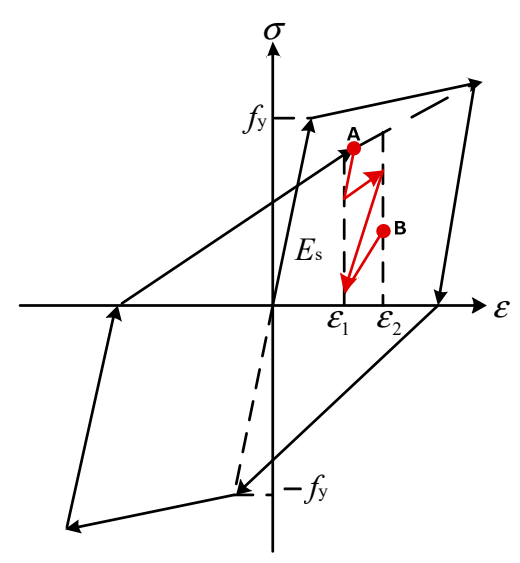

Figure 3. The stress error of steel under cyclic loading. 
2.1.2. Confined Constitutive Model of Concrete with a Square Steel Tube

The constitutive model of concrete confined by a square steel tube from Reference [42] is implemented, as shown in Figure 4. This model can be expressed by the following formula.

$$
\begin{gathered}
y=\left\{\begin{array}{cc}
2 x-x^{2} & x \leq 1 \\
\frac{x}{\beta(x-1)^{\eta}+x} & x>1
\end{array}\right. \\
x=\frac{\varepsilon}{\varepsilon_{0}} \\
y=\frac{\sigma}{\sigma_{0}} \\
\sigma_{0}=\left[1+\left(-0.0135 \xi^{2}+0.1 \xi\right) \cdot\left(\frac{24}{f_{c}^{\prime}}\right)^{0.45}\right] \cdot f_{c}^{\prime}
\end{gathered}
$$

where $\xi=A_{s} f_{y} / A_{c} f_{c k}$ in which $A_{s}$ is the cross-sectional area of the steel tube, $f_{y}$ is the yield stress of the steel tube, $A_{c}$ is the cross-sectional area of the core concrete, and $f_{c k}$ is the uniaxial compressive strength of the concrete. $\varepsilon_{0}$ is the peak strain of the confined concrete, $\sigma_{0}$ is the peak stress of the confined concrete, $f_{c}{ }^{\prime}$ is the cylindrical compressive strength of the unconfined concrete, and $\beta$ represents the parameter of the descending branch.

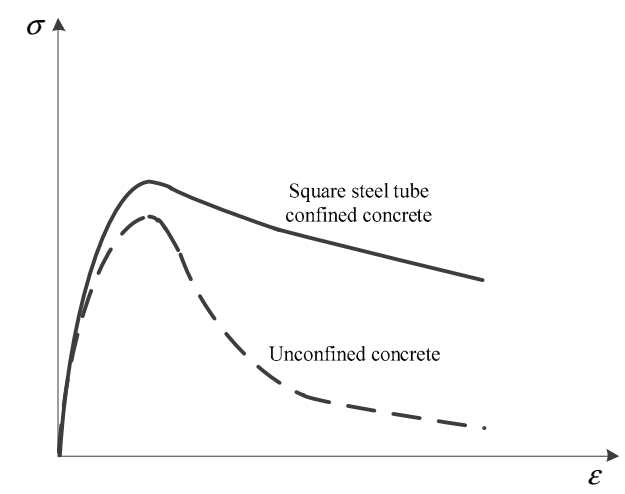

Figure 4. The constitutive model of concrete confined by a square steel tube.

\subsection{Strain Rate Effect}

The rate sensitivities of steel and concrete materials in building structures subject to strong ground motions have been demonstrated in previous studies $[9,13,14,18,43-45]$. The mechanical properties of steel and concrete can be affected by the loading rate in the following aspects: (1) the yield strength and ultimate strength of steel increase with a growing strain rate, (2) as the strain rate increases, the tensile strength, compressive strength, and elastic modulus of the concrete grow, which induces the deformation behavior of the concrete to change to a certain extent, (3) with an increasing strain rate, the concrete crack propagation mechanism changes significantly. As a result, the damage characteristics of RC components are affected [12]. The failure mechanism and damage evolution process of the CFST 
structure, with concrete and steel as the main building materials, are bound to be affected by the loading rate. The action of earthquake sequences may aggravate the strain rate effect, so structural analysis based on the static constitutive relationships of the materials is bound to have considerable errors.

\subsubsection{Strain Rate Effect of Steel}

Currently, there are few studies on the influence of the strain rate on the nonlinear analysis of structures, and the constitutive model of metal plastic material in ABAQUS can consider the impact of the strain rate only on the yield strength or ultimate strength. To address this issue, a subroutine for steel that can effectively consider the effect of strain rate is developed in this study. Existing studies have shown that the yield strength, tensile strength, ultimate strain, and slope of the hardening branch of the stress-strain curve of steel are all influenced by the strain rate. In addition, when the strain rate changes during loading, the shape of the hysteresis loop changes to a certain extent, and the area of the hysteresis loop increases with a rising strain rate [9,41]. Considering only the influence of the strain rate on the yield strength and, in particular, modifying only the strength using the dynamic increase factor method cannot accurately describe the influence of the time-varying strain rate on the mechanical properties of steel and ignores some important factors relatively sensitive to the strain rate. To address this problem, the following issues are considered in this study.

The influences of the strain rate on the yield strength and tensile strength are considered in real time. According to the actual needs, different dynamic constitutive models can be selected for the strain rate effect of steel. In this study, the dynamic tensile constitutive model of steel provided in Reference [17] is selected, as shown in the following formulas.

$$
\begin{gathered}
\frac{f_{y d}}{f_{y s}}=1+c_{f} \lg \frac{\dot{\varepsilon}}{\dot{\varepsilon}_{0}} \\
\frac{f_{u d}}{f_{u s}}=1+c_{u} \lg \frac{\dot{\varepsilon}}{\dot{\varepsilon}_{0}} \\
c_{f}=0.1709-3.289 \times 10^{-4} f_{y s} \\
c_{u}=0.02738-2.982 \times 10^{-5} f_{y s}
\end{gathered}
$$

where $\dot{\varepsilon}$ is the strain rate, $\dot{\varepsilon}_{0}$ denotes the quasi-static strain rate, $f_{y s}$ and $f_{y d}$ are the quasi-static and dynamic yield strength, respectively, and $f_{u s}$ and $f_{y d}$ are the quasi-static and dynamic ultimate tensile strength, respectively.

The influence on the slope of the hardening branch of the steel stress-strain curve due to strain rate is directly considered by substituting Equations (12)-(14) into those representing the skeleton curve. The influence of the strain rate on the area of the hysteresis loop is considered by correcting the historical maximum strain and stress. The strain of steel consists of elastic strain $\varepsilon_{e}$ and plastic strain $\varepsilon_{p}$. Therefore, the historical maximum strain $\varepsilon_{u n}$ at a certain strain rate is equal to the sum of the historical maximum plastic strain in this direction and the elastic strain $\sigma_{u n} / E_{s}$ under this strain rate. The historical maximum stress $\sigma_{u n}$ is taken as $f_{y}+\Delta \sigma$, where $\Delta \sigma$ is the product of the historical maximum plastic strain and the slope of the hardening branch under a quasi-static state. Additionally, the influence of the strain rate on the elastic modulus, plastic strain, and strain rate history are ignored because no consistent conclusions were obtained in previous studies.

When a structure is subjected to dynamic loading (e.g., seismic load) with a varying loading rate in real time, the loading path of steel may repeatedly switch between elastic loading and elastoplastic loading. The stress of the steel dramatically varies in real time, which necessitates the consideration of the strain rate's influence on the elastic ultimate strain. To ensure the stability of the numerical results and the accuracy of the constitutive model, the following considerations are examined.

(1) Monotonic loading 
As shown in Figure 5a, loading is assumed to be carried out at a relatively high strain rate $\dot{\varepsilon}_{\mathrm{H}}$ to point $A$, where the strain $\varepsilon_{\mathrm{A}}$ is higher than the elastic ultimate strain $\varepsilon_{\mathrm{e}, \mathrm{S}}$ under the quasi-static strain rate and lower than the elastic ultimate strain $\varepsilon_{\mathrm{e}, \mathrm{H}}$ corresponding to the current strain rate. When the strain rate drops suddenly to $\dot{\varepsilon}_{\mathrm{M}}$ and loading continues to point $B$, the strain at this point is $\varepsilon_{\mathrm{B}}$, which exceeds the elastic strain $\varepsilon_{\mathrm{e}, \mathrm{M}}$ corresponding to $\dot{\varepsilon}_{\mathrm{M}}$. This is a process in which the elastic deformation at high strain rates is transformed to elastoplastic deformation at low strain rates. After loading continues at a strain rate $\dot{\varepsilon}_{\mathrm{M}}$ to point $C$, the following situations may occur: (1) when the strain rate increases to $\dot{\varepsilon}_{\mathrm{H}}$, the loading first goes elastically along the path from point $C$ to point $\mathrm{D}$. The loading then continues at the strain rate $\dot{\varepsilon}_{\mathrm{H}}$ along the hardening skeleton curve to failure. (2) When the strain rate decreases to $\dot{\varepsilon}_{\mathrm{L}}$, considering that stress relaxation may occur during the process from high-speed loading to low-speed loading, in which case the strain remains the same, the stress first decreases from point $C$ to below $E$, and loading is carried out at the strain rate $\dot{\varepsilon}_{\mathrm{L}}$ along the direction from point $\mathrm{E}$ to $\mathrm{F}$ of the skeleton curve to failure.

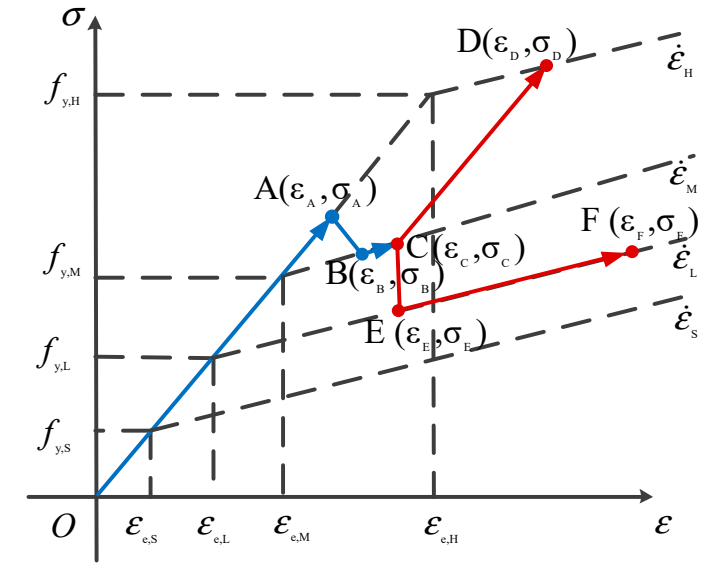

(a) Monotonic loading

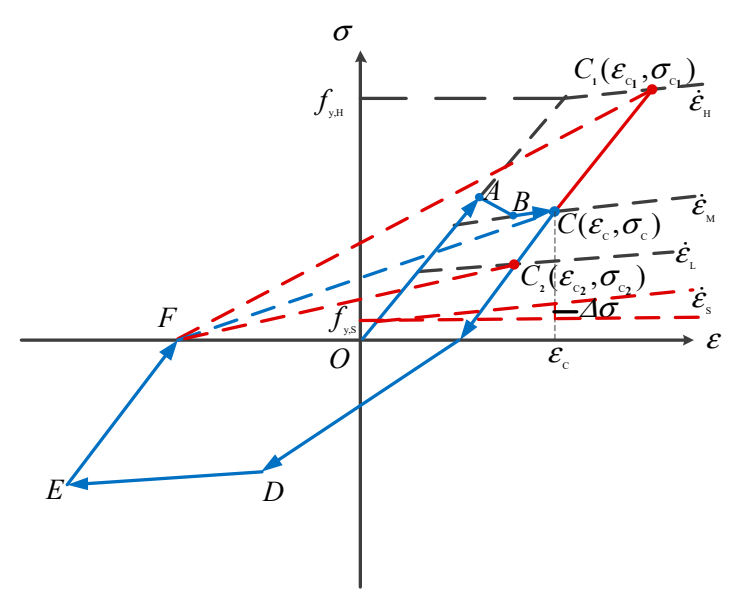

(b) Cyclic loading

Figure 5. Considerations of the strain-rate effect in steel subroutine.

(2) Cyclic loading

As shown in Figure $5 \mathrm{~b}$, loading is assumed to be carried out at a relatively high strain rate $\dot{\varepsilon}_{H}$ from point $O$ to point $A$ and then at a relatively low strain rate $\dot{\varepsilon}_{M}$ from point $A$ to point $C$, after which unloading is performed. At this time, point $C$ is the historical maximum strain point in the tension direction. The steel continues to undergo unloading, reverse reloading, and unloading again to reach point F: (1) When the strain rate increases to $\dot{\varepsilon}_{H}$, the historical maximum strain point in this direction changes from point $C$ to point $C_{1}$. In this case, the stress and strain of $C_{1}$ should be redefined according to the strain rate $\dot{\varepsilon}_{H}$. The reinforcing steel strain is composed of elastic strain and plastic strain. The strain of point $C_{1}$ is equal to the sum of the historical maximum plastic strain and the elastic strain, and the stress at point $C_{1}$ is the sum of the yield stress at the strain rate $\dot{\varepsilon}_{H}$. The total stress increment $\Delta \sigma$ after the hardening branch enters monotonic loading at a quasi-static strain rate $\dot{\varepsilon}_{S}$. (2) When the strain rate decreases to $\dot{\varepsilon}_{L}$, the historical maximum strain point changes from point $C$ to point $C_{2}$. The method for calculating the stress and strain of point $C_{2}$ is the same as that for point $C_{1}$. (3) When the strain rate is $\dot{\varepsilon}_{M}$, the loading path is directly pointed to the maximum historical strain point $C$ of the last cycle.

\subsubsection{Strain Rate Effect of Concrete}

As mentioned above, as the strain rate increases, the uniaxial tensile strength, compressive strength, and elastic modulus of concrete all increase to various degrees. Therefore, the influences of strain rate on the material properties of concrete are considered in the following aspects. 
The equations of both tension and compression skeleton curves are functions of the strength and elastic modulus. Therefore, the influence of the strain rate on concrete can be considered in real-time by updating only the tensile strength, compressive strength, and elastic modulus in real-time, according to the actual strain rate for the loading stress of the skeleton curve. The influence of the strain rate on the compressive and tensile strengths of concrete are manifested as the dynamic compressive strength, dynamic tensile strength, and dynamic elastic modulus, according to References [46-48], as shown in Formulas (16) through (18).

$$
\begin{gathered}
\frac{f_{c d}}{f_{c s}}=1.0+0.0648 \lg \frac{\dot{\varepsilon}_{c}}{\dot{\varepsilon}_{\mathcal{~}}} \\
\frac{f_{t d}}{f_{t s}}=1.0+0.057 \lg \frac{\dot{\varepsilon}_{t}}{\dot{\varepsilon}_{t s}} \\
\frac{E_{c}^{d}}{E_{c}^{s}}=1.0+0.0519 \lg \frac{\dot{\varepsilon}_{c}}{\dot{\varepsilon}_{c s}}
\end{gathered}
$$

where $f_{c d}$ and $f_{c s}$ are the dynamic and quasi-static compressive strength, respectively. $f_{t d}$ and $f_{t s}$ denote the dynamic and quasi-static tensile strength, respectively. $\dot{\varepsilon}_{t}$ and $\dot{\varepsilon}_{c}$ are the tensile and compressive strain rate, respectively. $\dot{\varepsilon}_{t s}$ and $\dot{\varepsilon}_{c s}$ denote the tensile and compressive quasi-static strain rate, respectively. $E_{c}^{d}$ and $E_{c}^{s}$ are dynamic and quasi-static Young's modulus, respectively.

For the stress in the reloading branch of concrete in tension and in compression, the strain rate does not affect the existing damage of the concrete. Therefore, regardless of the variation in the loading rate, the tensile and compressive reloading stiffness are all determined by the unloading stiffness of the last skeleton curve, that is, the reloading stress is determined by the last unloading stiffness. Currently, no consistent conclusions on the influence of the strain rate on concrete strain have been reached. Therefore, the influence of the strain rate on the concrete strain is ignored in this study.

\section{Effect of Strain Rate and BRB on Seismic Response of a CFST Frame Structure}

\subsection{Description of the Finite Element Model}

A 12-story CFST frame is selected as the exemplar structure. The structure has a height of $4.2 \mathrm{~m}$ for the first story and a height of $3.6 \mathrm{~m}$ for each of the other stories, totaling $43.8 \mathrm{~m}$. The plan view and elevation of the structure are shown in Figure 6. The seismic fortification intensity is 7 and the designed basic acceleration of the ground motion is $0.15 \mathrm{~g}$ (as specified in [40]). The floor/roof dead load and live load are set to be $4.5 \mathrm{kN} / \mathrm{m}^{2}$ and $2.0 \mathrm{kN} / \mathrm{m}^{2}$, respectively, which are converted to the density applied on the floor/roof slabs. A $140 \mathrm{~mm}$-thick slab with a concrete strength grade of C30 (i.e., a nominal cubic compressive strength of $30 \mathrm{Mpa}$ ) is used for both the floors and the roof. The transverse and longitudinal steel beams are Q235 (i.e., the yield strength of steel is $235 \mathrm{Mpa}$ ) I-beams that have cross-sectional dimensions of $700 \mathrm{~mm} \times 300 \mathrm{~mm} \times 13 \mathrm{~mm} \times 24 \mathrm{~mm}$. The CFST column has cross-sectional dimensions of $500 \mathrm{~mm} \times 500 \mathrm{~mm}$, with a tube of Q345 steel and infilled concrete of strength grade C30. The thickness of the steel tube is $20 \mathrm{~mm}$ for the columns in stories 1 to 5 and $15 \mathrm{~mm}$ for the columns in stories 6 to 12. The planar frame along grid line 3 is used for analysis. CSFT-A is an ordinary CFST frame, and CSFT-B is a CFST frame with BRBs in each end bay.

The FE models of CSFT-A and CSFT-B are established using the ABAQUS software program. The steel beams, steel tubes, and infilled concrete are modeled using the three-dimensional linear interpolation beam element (B31). The beam and column elements are connected by rigid joints. The BRBs are simulated using the three-dimensional two-nodes truss element (T3D2), and the relevant parameters are set based on Reference [49]. The previously mentioned dynamic fiber element model of the CFST member is used for analysis. The constitutive model of square steel tube-confined concrete proposed in Reference [42] is used for the concrete, and the bilinear hardening constitutive model recommended in the "Code for Design of Concrete Structures (GB50010-2010)" is selected for the steel. Three sets of real ground motion records, San Fernando (1971), Taft (1952), and Gengmaa (1988) are 
used as ground motion inputs. It should be noted that the flexibility of beam-column joint may impact the seismic response of the CFST structure [50]. In this case, the rigid beam-column joint is employed in the design of the exemplar CFST structure. Thus, the joint is modeled as rigid in the numerical simulation and its flexibility on the structural seismic performance is neglected.

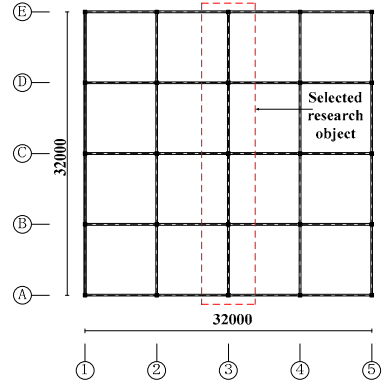

(a) Plan view

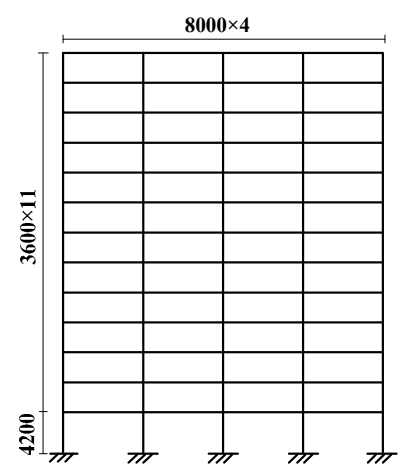

(b) Elevation view of CSFT-A

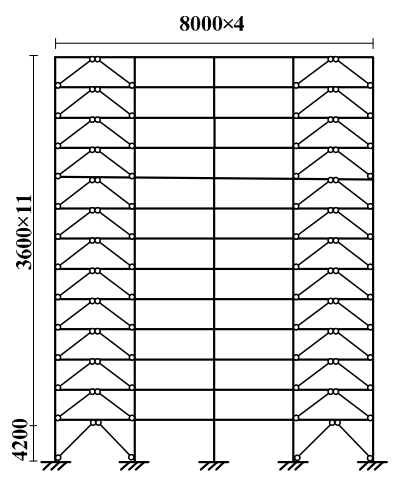

(c) Elevation view of CSFT-B

Figure 6. Layout of the exemplar structures (unit: $\mathrm{mm}$ ).

\subsection{Analysis of the Influence of the Strain Rate on the Seismic Response of the CFST Structure}

In this subsection, the nonlinear seismic responses of CSFT-A are analyzed with and without consideration of the strain rate effect. The maximum roof displacement and the inter-story drift ratios (ISDRs) are used as the structural response indexes to extract the time history analysis results. Table 1 lists the maximum roof displacement and ISDRs of the structure with and without the strain rate effect and the corresponding differences. Figures 7-10 show the structural dynamic responses under the Taft ground motion with different peak ground accelerations (PGAs). The results show that, as the PGA increases, the differences between the maximum roof displacement and ISDRs of the structure with and without the strain rate effect gradually increase. For a PGA of $0.2 \mathrm{~g}$, the structural response curve basically coincides with each other for the two cases, which indicates that the effect of the strain rate is not remarkable. This is because, under low seismic excitation, the concrete does not experience tensile cracking, and the overall structure is still in a linear elastic stage, so the strain rate effect is not remarkable. For a PGA higher than $0.2 \mathrm{~g}$, the results considering and not considering the strain rate effect are very different. As seen in the table, when considering the strain rate, the roof displacement and maximum ISDR of the structure are much lower, and the corresponding maximum differences are $10.2 \%$ and $6.9 \%$, respectively.

In short, the influence of the strain rate on the structural response is not remarkable in the elastic stage. However, as the structure enters the nonlinear stage, considering the strain rate increases the strength and energy dissipation performance of the material and, thus, improves the structural resistance, which reduces the structural response. Considering the influence of the strain rate can more reasonably reflect the actual stress state of the structure and make the analysis results more accurate. Therefore, the influence of strain rate should be properly considered in structural seismic analysis and design. 
Table 1. The influence of strain rate on a structural seismic response.

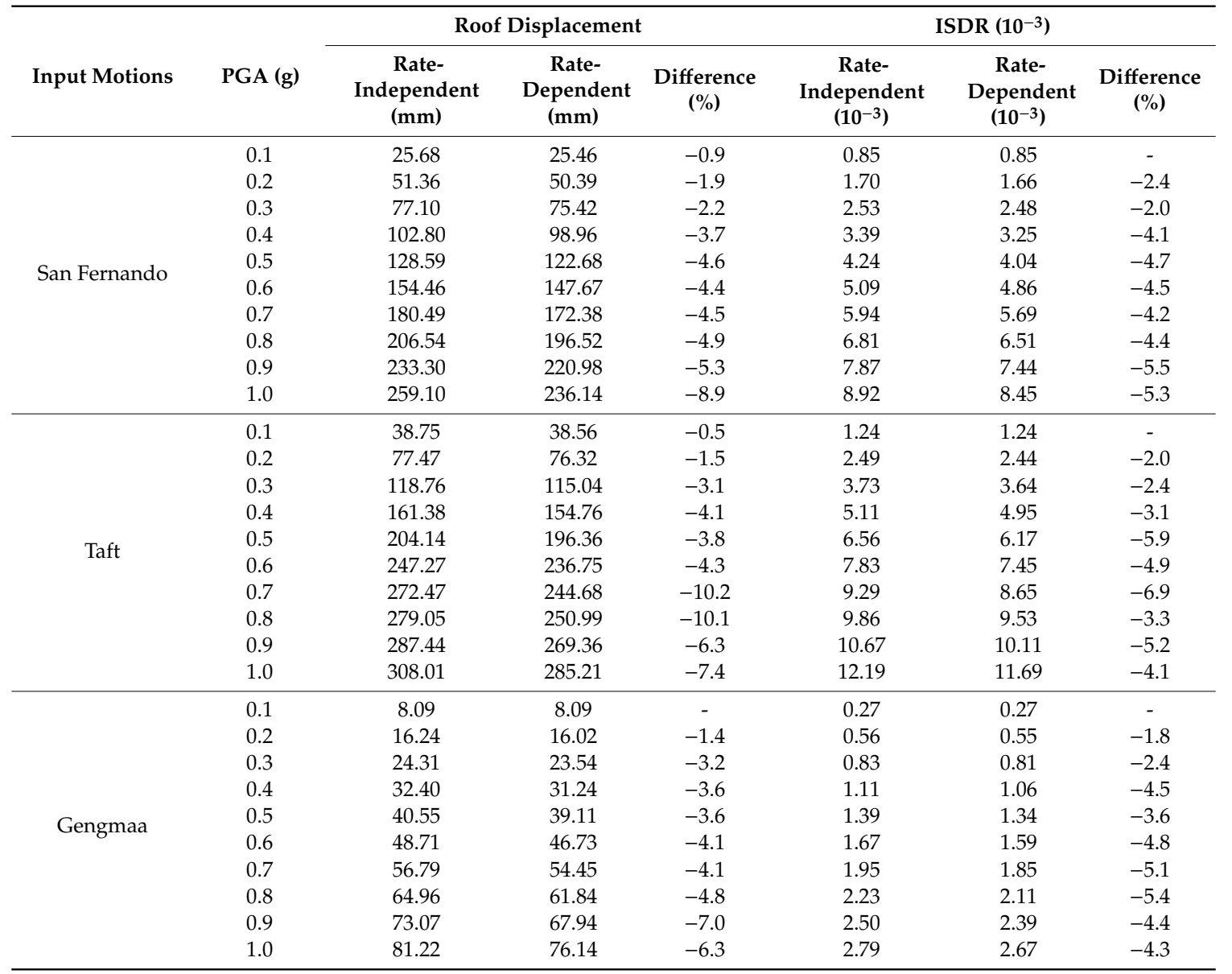

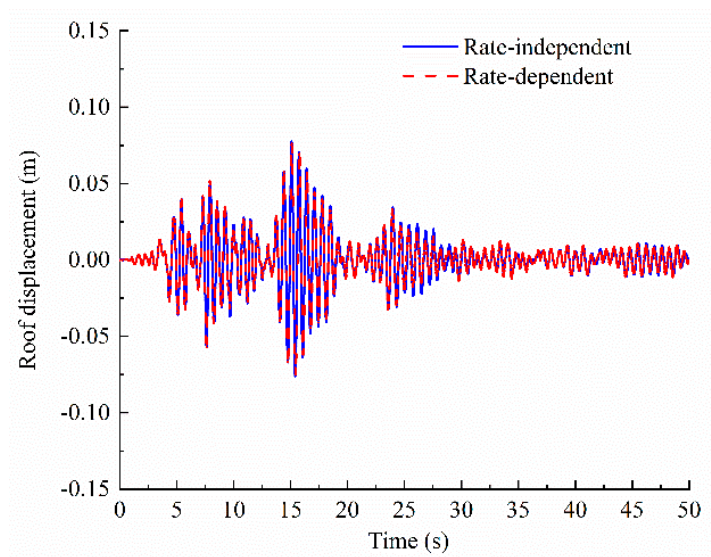

(a) Roof displacement

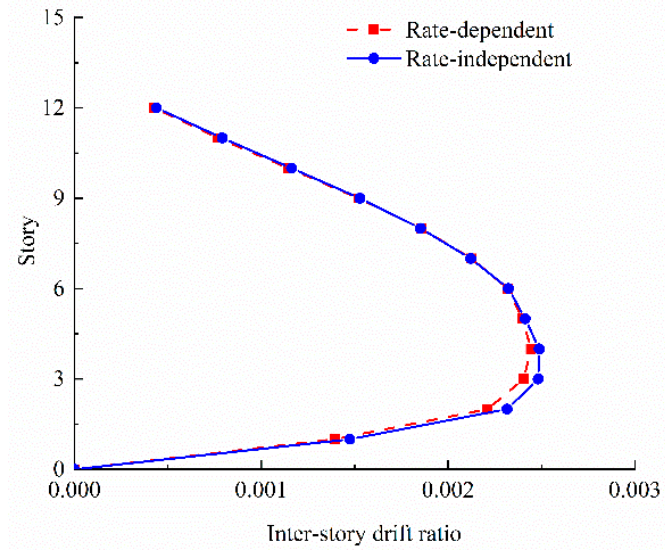

(b) ISDRs

Figure 7. Comparison of the rate-dependent and rate-independent numerical results of roof displacement and an inter-story drift ratio (Taft PGA $=0.2 \mathrm{~g}$ ). 


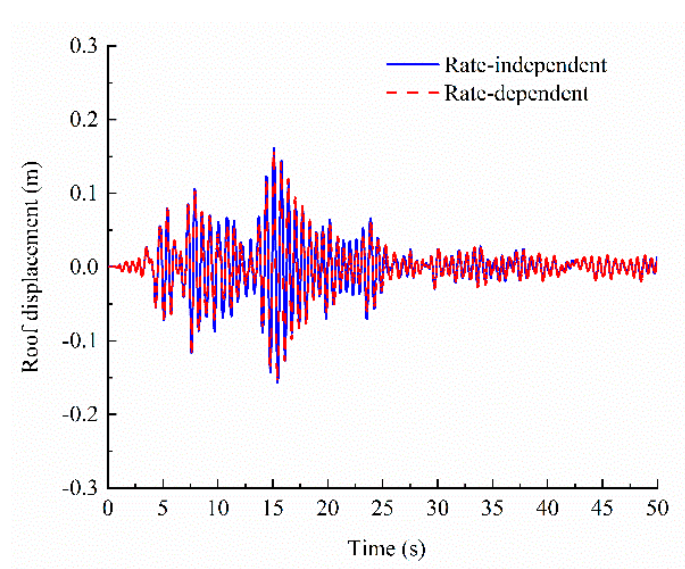

(a) Roof displacement

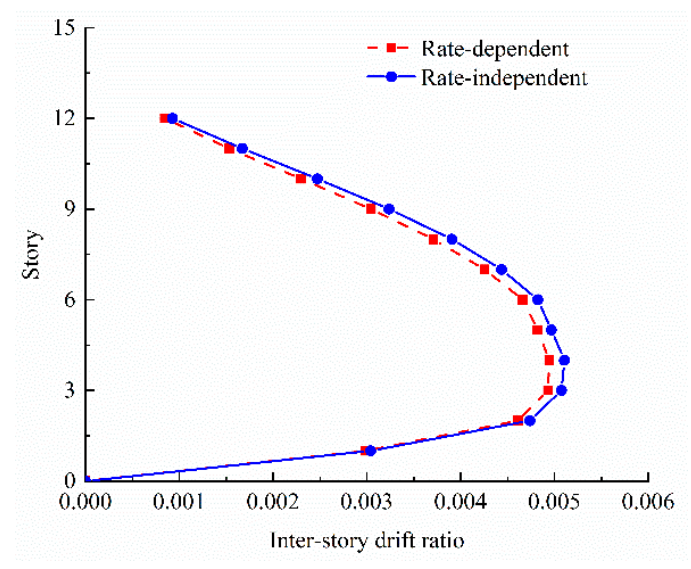

(b) ISDRs

Figure 8. Comparison of the rate-dependent and rate-independent numerical results of roof displacement and ISDRs (Taft PGA $=0.4 \mathrm{~g}$ ).

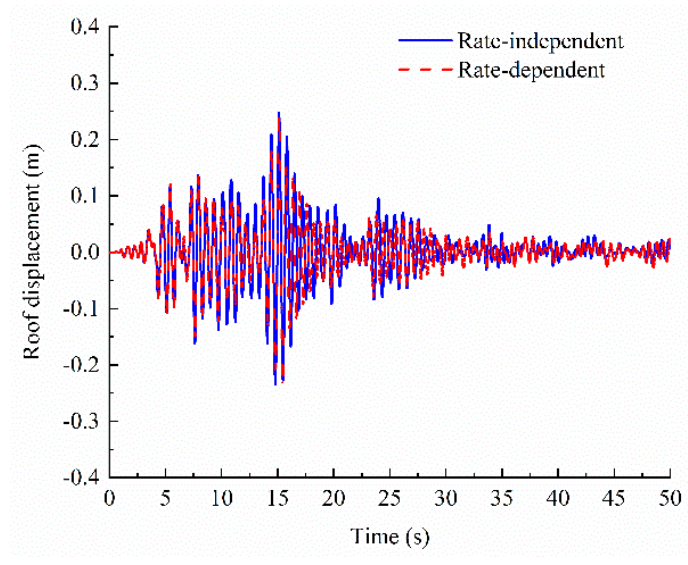

(a) Roof displacement

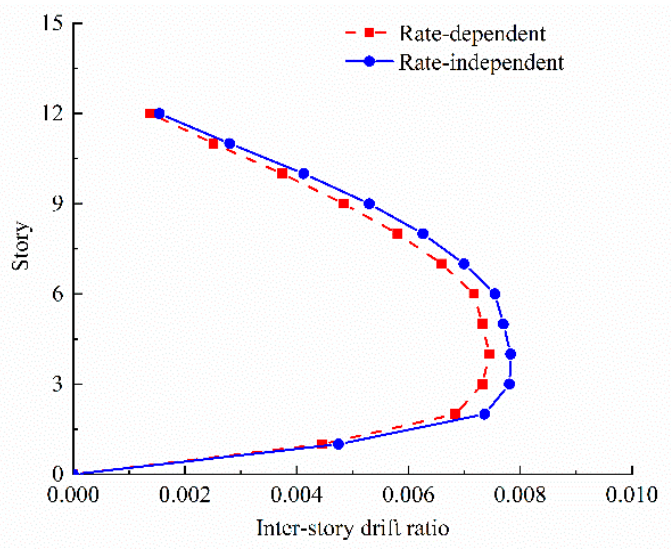

(b) ISDRs

Figure 9. Comparison of the rate-dependent and rate-independent numerical results of roof displacement and ISDRs (Taft PGA $=0.6 \mathrm{~g}$ ).

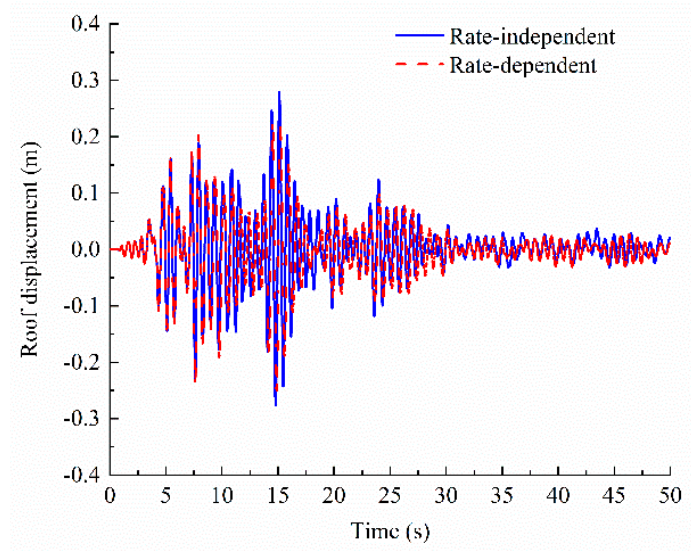

(a) Roof displacement

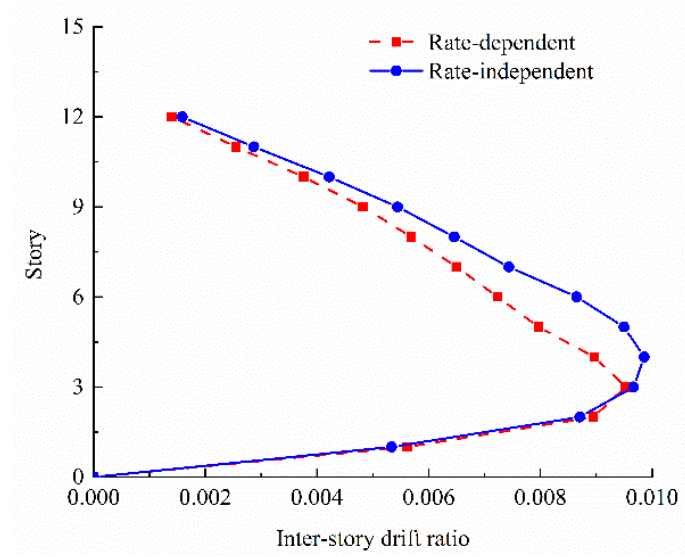

(b) ISDRs

Figure 10. Comparison of the rate-dependent and rate-independent numerical results of roof displacement and ISDRs (Taft PGA $=0.8 \mathrm{~g}$ ). 


\subsection{Influence of BRBs on the Seismic Response of the CFST Structure}

BRBs are a type of metal damper. By providing a restraining casing that surrounds an ordinary brace, the buckling of the brace under compression can be suppressed without limiting the free expansion and contraction of the brace under stress, so that the brace can yield over the entire cross section either in compression or in tension. Through reasonable design, BRBs can yield first under a strong earthquake. The input seismic energy is dissipated through the hysteresis of the BRBs to protect the main frame structure.

The CFST structure without BRB (CFST-A) and the CFST structure with BRBs (CFST-B) are used in the nonlinear seismic response analysis. The maximum roof displacement and ISDR are taken as the structural response indexes to extract the time history analysis results. Table 2 lists the maximum roof displacements and ISDRs of CFST-A and CFST-B and the corresponding reduction percentages (RPs) under various conditions. The results show that the responses of CFST-B are generally smaller than those of CFST-A. Specifically, the maximum roof displacement decreases by $14.1 \%$ to $42.7 \%$, and the maximum ISDR decreases by $21.5 \%$ to $40.2 \%$.

Table 2. The comparison of a structural response between CFST-A and CFST-B.

\begin{tabular}{|c|c|c|c|c|c|c|c|}
\hline \multirow{2}{*}{ Input Motions } & \multirow{2}{*}{ PGA (g) } & \multicolumn{3}{|c|}{ Roof Displacement (mm) } & \multicolumn{3}{|c|}{ ISDR $\left(10^{-3}\right)$} \\
\hline & & CFST-A & CFST-B & Difference (\%) & CFST-A & CFST-B & Difference (\%) \\
\hline \multirow{10}{*}{ San Fernando } & 0.1 & 25.46 & 19.34 & -24.0 & 0.85 & 0.64 & -24.7 \\
\hline & 0.2 & 50.39 & 38.65 & -23.3 & 1.66 & 1.27 & -23.5 \\
\hline & 0.3 & 75.42 & 57.77 & -23.4 & 2.48 & 1.91 & -23.0 \\
\hline & 0.4 & 98.96 & 76.94 & -22.3 & 3.25 & 2.53 & -22.2 \\
\hline & 0.5 & 122.68 & 95.91 & -21.8 & 4.04 & 3.17 & -21.5 \\
\hline & 0.6 & 147.67 & 114.78 & -22.3 & 4.86 & 3.80 & -21.8 \\
\hline & 0.7 & 172.38 & 133.86 & -22.3 & 5.69 & 4.45 & -21.8 \\
\hline & 0.8 & 196.52 & 152.72 & -22.3 & 6.51 & 5.09 & -21.8 \\
\hline & 0.9 & 220.98 & 171.80 & -22.3 & 7.44 & 5.71 & -23.3 \\
\hline & 1.0 & 236.14 & 190.80 & -19.2 & 8.45 & 6.32 & -25.2 \\
\hline \multirow{10}{*}{ Taft } & 0.1 & 38.56 & 22.95 & -40.5 & 1.24 & 0.76 & -38.7 \\
\hline & 0.2 & 76.32 & 45.75 & -40.1 & 2.44 & 1.49 & -38.9 \\
\hline & 0.3 & 115.04 & 67.85 & -41.0 & 3.64 & 2.18 & -40.1 \\
\hline & 0.4 & 154.76 & 90.69 & -41.4 & 4.95 & 2.96 & -40.2 \\
\hline & 0.5 & 196.36 & 113.21 & -42.3 & 6.17 & 3.71 & -39.9 \\
\hline & 0.6 & 236.75 & 135.69 & -42.7 & 7.45 & 4.48 & -39.9 \\
\hline & 0.7 & 244.68 & 158.59 & -35.2 & 8.65 & 5.21 & -39.8 \\
\hline & 0.8 & 250.99 & 182.60 & -27.2 & 9.53 & 6.03 & -36.7 \\
\hline & 0.9 & 269.36 & 202.90 & -24.7 & 10.11 & 6.68 & -33.9 \\
\hline & 1.0 & 285.21 & 226.60 & -20.5 & 11.69 & 7.62 & -34.8 \\
\hline \multirow{10}{*}{ Gengmaa } & 0.1 & 8.09 & 6.48 & -19.9 & 0.27 & 0.20 & -25.9 \\
\hline & 0.2 & 16.02 & 12.96 & -19.1 & 0.55 & 0.40 & -27.3 \\
\hline & 0.3 & 23.54 & 19.30 & -18.0 & 0.81 & 0.61 & -24.7 \\
\hline & 0.4 & 31.24 & 25.77 & -17.5 & 1.06 & 0.79 & -25.5 \\
\hline & 0.5 & 39.11 & 32.28 & -17.5 & 1.34 & 0.98 & -26.9 \\
\hline & 0.6 & 46.73 & 38.75 & -17.1 & 1.59 & 1.21 & -23.9 \\
\hline & 0.7 & 54.45 & 45.14 & -17.1 & 1.85 & 1.38 & -25.4 \\
\hline & 0.8 & 61.84 & 51.67 & -16.4 & 2.11 & 1.55 & -26.5 \\
\hline & 0.9 & 67.94 & 58.35 & -14.1 & 2.39 & 1.75 & -26.8 \\
\hline & 1.0 & 76.14 & 64.73 & -15.0 & 2.67 & 1.98 & -25.8 \\
\hline
\end{tabular}

Figure 11 compares the roof displacement time history curve and ISDRs of CFST-A and CFST-B under Taft ground motion (PGA $=1.0 \mathrm{~g}$ ). The maximum values of the roof displacement and ISDR of CFST-B are smaller than those of CFST-A. The ISDRs of CFST-B significantly decrease compared with those of CFST-A. Under the Taft ground motion, the maximum ISDR of CFST-B is $7.62 \times 10^{-3}$, with a decrease of $37.5 \%$ compared with that of CFST-B. 


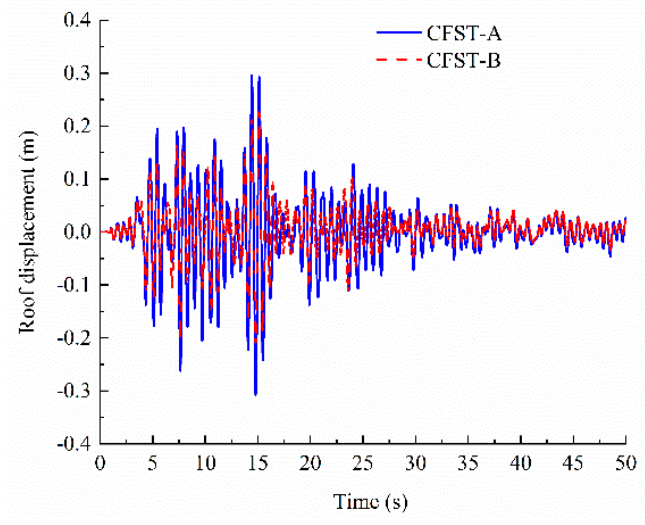

(a) Roof displacement

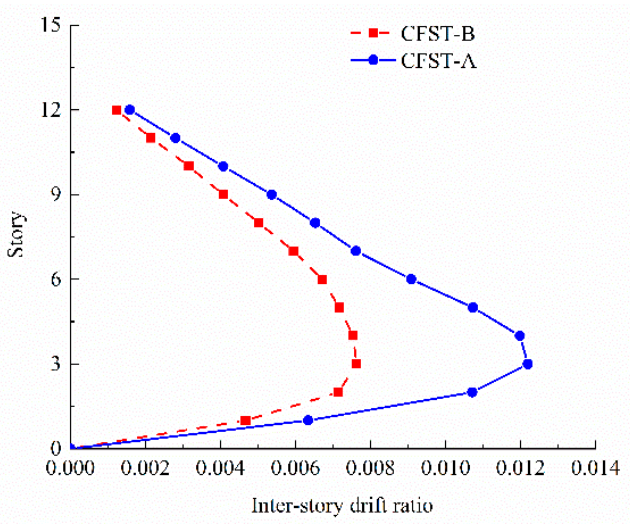

(b) ISDRs

Figure 11. Comparison of the roof displacement and ISDRs between CFST-A and CFST-B (Taft PGA = 1.0 g).

\section{Seismic Response CFST Structure with BRBs under Earthquake Sequences}

\subsection{Sequence-Type Ground Motion}

An earthquake sequence is formed by multiple earthquake ground motions composed of foreshock, mainshock, and aftershock or a combination thereof (e.g., mainshock and aftershock). The sequence-type ground motions constructed in this study refer to an earthquake sequence that comprises a large earthquake (mainshock), with a foreshock before the mainshock and an aftershock after the mainshock. Due to the lack of actual recorded sequence-type ground motions, most researchers rely on synthetic methods to construct earthquake sequences. To date, the main synthetic methods are divided into two types, which include the repetition method and the randomized method. The principle of the repetition method is to equate the characteristics of the aftershocks (foreshocks) with those of the mainshock and consider the aftershocks (foreshocks) as one or more repetitions of the mainshock to form an earthquake sequence. In contrast, the principle of the randomized method is to randomly select an earthquake from the non-mainshock set to be aftershocks or foreshocks.

In this study, the repeated method is employed to construct foreshock-mainshock-aftershock sequences. Based on the Gutenberg Richter law [51,52], a real ground motion is selected as the mainshock, and the PGA of the mainshock is scaled for the aftershocks (foreshocks) with a specific scaling coefficient. As suggested by Hatzigeorgiou [51], the PGA scaling coefficient $(\delta)$ can be derived without the involvement of specific information of ground motion records. However, the recommended $\delta$ of 0.8526 possibly overestimates the intensities of the foreshocks and aftershocks, which poses certain limitations. Considering the uncertainty of the ratios between the PGAs of the foreshocks (aftershocks) and the mainshock, $\delta$ is taken as $0.4,0.6$, and 0.8 in this study, respectively, to investigate the influence of this parameter on the structural seismic responses.

Between two consecutive seismic events, a time interval is generally applied to better simulate the actual scenario of an earthquake sequence. If the time gap is very short or neglected, it is possible that the structure is not at rest when the subsequent earthquake excitation initiates, which aggravates the errors between the simulation and the actual situation. On the other hand, an excessively long time interval between two consecutive seismic events reduces the calculation efficiency. To balance error reduction in simulation and efficiency improvement in the calculation, a time interval of $50 \mathrm{~s}$ is applied in this study to give the structure enough time to stop the vibration of the structure due to damping.

\subsection{Nonlinear Response Analysis under Sequence-Type Ground Motion}

As discussed in Section 3.3, the BRBs can significantly reduce the seismic responses of the CFST frame structure. Thus, in the following analysis, this paper focuses on the CFST frame with BRBs and only the influence of the earthquake sequence on CFST-B is presented due to space limitations. It is 
noted that both the CFST frame with and without BRBs yielded similar results regarding the effect of the earthquake sequence. In this case, the seismic response analysis of CFST-B is performed with consideration of the strain rate effect using 30 sets of earthquake sequences. The seismic responses of the structure under the single mainshock and under different earthquake sequences $(\delta=0.4,0.6$, and 0.8$)$ are compared to analyze the effect of the earthquake sequence on the seismic response of the structure. The comparison results from the structural dynamic response analyses are listed in Tables 3 and 4 . Figure 12 compares the response curves of the CFST frame structure with BRBs under ground motion with an ID of A-CAS (PGA $=0.332 \mathrm{~g}$ ). It is shown that the maximum roof displacements of the structure generally occur during the mainshock segments. Under the same earthquake sequence, with increasing $\delta$, the maximum roof displacement of the structure gradually increases. The foreshock leads to certain cumulative damage of the structure. As $\delta$ increases, the level of cumulative damage increases. Figure 13 compares the ISDRs of CFST-B under ground motion A-CAS (PGA $=0.332 \mathrm{~g}$ ). The ISDRs under the mainshock and under earthquake sequences with $\delta=0.4,0.6$, and 0.8 are compared, respectively. It is observed that, under the single mainshock and under earthquake sequences, the ISDR of the third story is generally larger than those of the other stories. Therefore, the third story is the weakest story of the structure. With increasing $\delta$, the maximum ISDR of the structure caused by the earthquake sequence gradually increases. To further comparatively analyze the seismic responses of the structure subjected to single mainshocks and earthquake sequences, Tables 3 and 4 compare the maximum roof displacement and the maximum ISDRs under different ground motions.

Table 3. Maximum roof displacement under mainshock and earthquake sequence.

\begin{tabular}{|c|c|c|c|c|c|c|c|c|}
\hline \multirow[b]{2}{*}{$\begin{array}{c}\text { Input } \\
\text { Motions }\end{array}$} & \multirow[b]{2}{*}{ PGA (g) } & \multicolumn{7}{|c|}{ Roof Displacement (mm) } \\
\hline & & $\begin{array}{c}\text { Mainshock } \\
\text { Only }\end{array}$ & $\begin{array}{c}\text { Earthquake } \\
\text { Sequence } \\
(\delta=0.4)\end{array}$ & $\begin{array}{c}\text { Difference } \\
(\%)\end{array}$ & $\begin{array}{c}\text { Earthquake } \\
\text { Sequence } \\
(\delta=0.6)\end{array}$ & $\begin{array}{c}\text { Difference } \\
(\%)\end{array}$ & $\begin{array}{c}\text { Earthquake } \\
\text { Sequence } \\
(\delta=0.8)\end{array}$ & $\begin{array}{c}\text { Difference } \\
(\%)\end{array}$ \\
\hline M-AGW & 0.032 & 10.12 & 11.93 & 17.82 & 12.94 & 27.84 & 14.11 & 39.41 \\
\hline A-CAT & 0.042 & 21.14 & 22.54 & 6.62 & 23.61 & 11.68 & 24.82 & 17.41 \\
\hline A-STP & 0.049 & 23.18 & 26.65 & 14.95 & 26.66 & 15.00 & 31.47 & 35.75 \\
\hline HO6 & 0.060 & 13.42 & 14.61 & 8.88 & 15.75 & 17.42 & 18.79 & 40.08 \\
\hline A-CTS & 0.062 & 19.74 & 20.84 & 5.55 & 22.82 & 15.60 & 26.22 & 32.80 \\
\hline A-HAR & 0.070 & 47.32 & 48.08 & 1.62 & 51.35 & 8.53 & 57.41 & 21.35 \\
\hline $\mathrm{H}-\mathrm{CO} 8$ & 0.100 & 70.99 & 74.70 & 5.24 & 90.07 & 26.88 & 94.47 & 33.07 \\
\hline $\mathrm{H}-\mathrm{CC} 4$ & 0.115 & 36.09 & 43.62 & 20.88 & 52.29 & 44.88 & 53.64 & 48.62 \\
\hline H-CAL & 0.128 & 19.19 & 24.74 & 28.93 & 28.43 & 48.13 & 31.99 & 66.70 \\
\hline H-CMP & 0.144 & 69.19 & 73.94 & 6.87 & 86.52 & 25.04 & 92.26 & 33.34 \\
\hline BRA & 0.160 & 28.61 & 30.70 & 7.31 & 33.11 & 15.73 & 36.55 & 27.75 \\
\hline M-GMR & 0.184 & 12.15 & 15.98 & 31.56 & 20.19 & 66.18 & 20.40 & 67.90 \\
\hline M-G03 & 0.194 & 24.76 & 27.44 & 10.81 & 27.34 & 10.41 & 27.47 & 10.93 \\
\hline M-G02 & 0.200 & 42.15 & 53.57 & 27.09 & 49.71 & 17.94 & 56.94 & 35.09 \\
\hline A-DWN & 0.215 & 98.21 & 107.62 & 9.58 & 124.44 & 26.71 & 124.92 & 27.20 \\
\hline FLE & 0.237 & 56.93 & 68.62 & 20.54 & 79.27 & 39.24 & 89.22 & 56.71 \\
\hline $\mathrm{C} 08$ & 0.259 & 88.21 & 90.75 & 2.87 & 95.97 & 8.80 & 106.57 & 20.82 \\
\hline H-CHI & 0.269 & 153.27 & 180.49 & 17.76 & 194.00 & 26.58 & 235.07 & 53.37 \\
\hline A-BIR & 0.299 & 85.14 & 106.52 & 25.11 & 123.55 & 45.11 & 134.30 & 57.73 \\
\hline I-ELC & 0.309 & 205.51 & 208.51 & 1.46 & 229.05 & 11.45 & 255.67 & 24.41 \\
\hline A-CAS & 0.322 & 103.16 & 110.72 & 7.33 & 124.45 & 20.64 & 140.07 & 35.78 \\
\hline H-DLT & 0.349 & 108.68 & 123.62 & 13.75 & 134.69 & 23.93 & 159.73 & 46.97 \\
\hline HOL & 0.358 & 189.52 & 194.36 & 2.55 & 207.12 & 9.29 & 218.26 & 15.17 \\
\hline CAP & 0.395 & 120.07 & 122.69 & 2.18 & 126.24 & 5.14 & 143.24 & 19.30 \\
\hline G04 & 0.413 & 108.79 & 132.15 & 21.47 & 169.48 & 55.79 & 187.37 & 72.23 \\
\hline G03 & 0.547 & 169.79 & 174.69 & 2.89 & 180.37 & 6.23 & 259.14 & 52.62 \\
\hline SCS & 0.612 & 430.69 & 504.98 & 17.25 & 598.28 & 38.91 & 697.79 & 62.02 \\
\hline H-BCR & 0.780 & 197.14 & 214.99 & 9.05 & 243.75 & 23.64 & 259.11 & 31.44 \\
\hline RRS & 0.834 & 659.33 & 717.68 & 8.85 & 794.27 & 20.47 & 837.11 & 26.96 \\
\hline SPV & 0.939 & 272.37 & 286.98 & 5.36 & 292.49 & 7.39 & 356.46 & 30.87 \\
\hline
\end{tabular}


Table 4. Maximum ISDR under mainshock and earthquake sequence.

\begin{tabular}{|c|c|c|c|c|c|c|c|c|}
\hline \multirow[b]{2}{*}{$\begin{array}{c}\text { Input } \\
\text { Motions }\end{array}$} & \multirow[b]{2}{*}{ PGA (g) } & \multicolumn{7}{|c|}{ ISDR $\left(10^{-3}\right)$} \\
\hline & & $\begin{array}{c}\text { Mainshock } \\
\text { Only }\end{array}$ & $\begin{array}{l}\text { Earthquake } \\
\text { Sequence } \\
(\delta=0.4)\end{array}$ & $\begin{array}{l}\text { Difference } \\
(\%)\end{array}$ & $\begin{array}{l}\text { Earthquake } \\
\text { Sequence } \\
(\delta=0.6)\end{array}$ & $\begin{array}{c}\text { Difference } \\
(\%)\end{array}$ & $\begin{array}{l}\text { Earthquake } \\
\text { Sequence } \\
(\delta=0.8)\end{array}$ & $\begin{array}{c}\text { Difference } \\
(\%)\end{array}$ \\
\hline M-AGW & 0.032 & 0.42 & 0.52 & 21.92 & 0.58 & 36.44 & 0.62 & 45.62 \\
\hline A-CAT & 0.042 & 0.60 & 0.72 & 20.02 & 0.77 & 27.58 & 0.79 & 31.60 \\
\hline A-STP & 0.049 & 0.79 & 0.86 & 9.01 & 0.87 & 10.41 & 1.04 & 31.30 \\
\hline HO6 & 0.060 & 0.37 & 0.40 & 7.62 & 0.44 & 18.10 & 0.47 & 24.97 \\
\hline A-CTS & 0.062 & 0.60 & 0.69 & 15.78 & 0.70 & 17.71 & 0.85 & 41.82 \\
\hline A-HAR & 0.070 & 1.54 & 1.60 & 3.81 & 1.70 & 10.03 & 1.88 & 22.07 \\
\hline $\mathrm{H}-\mathrm{CO} 8$ & 0.100 & 2.30 & 2.46 & 6.89 & 2.95 & 28.33 & 3.24 & 41.06 \\
\hline H-CC4 & 0.115 & 1.23 & 1.40 & 13.55 & 1.66 & 34.46 & 1.76 & 42.45 \\
\hline H-CAL & 0.128 & 0.71 & 0.84 & 17.48 & 0.90 & 25.50 & 0.99 & 38.24 \\
\hline H-CMP & 0.144 & 2.51 & 2.62 & 4.29 & 3.02 & 20.36 & 3.55 & 41.12 \\
\hline BRA & 0.160 & 0.95 & 0.98 & 3.82 & 1.12 & 18.38 & 1.23 & 30.01 \\
\hline M-GMR & 0.184 & 0.68 & 0.73 & 6.23 & 0.78 & 13.84 & 0.80 & 17.08 \\
\hline M-G03 & 0.194 & 0.85 & 0.92 & 7.33 & 0.94 & 9.45 & 0.99 & 15.58 \\
\hline M-G02 & 0.200 & 1.20 & 1.48 & 23.13 & 1.59 & 32.30 & 1.68 & 39.64 \\
\hline A-DWN & 0.215 & 3.24 & 3.62 & 11.76 & 4.23 & 30.42 & 4.27 & 31.65 \\
\hline FLE & 0.237 & 2.20 & 3.11 & 41.26 & 3.20 & 45.45 & 3.48 & 58.03 \\
\hline $\mathrm{C} 08$ & 0.259 & 3.02 & 3.11 & 3.05 & 3.40 & 12.58 & 3.66 & 21.07 \\
\hline H-CHI & 0.269 & 4.01 & 5.19 & 29.29 & 5.99 & 49.31 & 6.06 & 50.94 \\
\hline A-BIR & 0.299 & 1.92 & 2.26 & 17.44 & 2.34 & 21.67 & 2.79 & 45.22 \\
\hline I-ELC & 0.309 & 6.90 & 8.70 & 26.09 & 9.50 & 37.69 & 10.11 & 46.55 \\
\hline A-CAS & 0.322 & 3.36 & 3.71 & 10.42 & 4.13 & 22.92 & 4.31 & 28.27 \\
\hline H-DLT & 0.349 & 0.93 & 1.40 & 51.47 & 1.55 & 67.01 & 1.63 & 76.23 \\
\hline $\mathrm{HOL}$ & 0.358 & 6.74 & 6.97 & 3.41 & 7.38 & 9.50 & 8.18 & 21.31 \\
\hline CAP & 0.395 & 3.87 & 4.10 & 5.94 & 4.27 & 10.34 & 4.59 & 18.64 \\
\hline G04 & 0.413 & 3.99 & 4.75 & 18.95 & 5.64 & 41.35 & 6.55 & 64.16 \\
\hline G03 & 0.547 & 21.23 & 22.83 & 7.54 & 26.75 & 25.98 & 30.88 & 45.46 \\
\hline SCS & 0.612 & 74.95 & 84.61 & 12.89 & 106.15 & 41.63 & 109.75 & 46.43 \\
\hline H-BCR & 0.780 & 27.60 & 29.02 & 5.14 & 30.24 & 9.57 & 34.99 & 26.79 \\
\hline RRS & 0.834 & 111.24 & 121.52 & 9.24 & 134.90 & 21.27 & 144.43 & 29.84 \\
\hline SPV & 0.939 & 34.97 & 36.02 & 2.99 & 37.53 & 7.32 & 41.76 & 19.43 \\
\hline
\end{tabular}

The numerical results show that, under the earthquake sequences with $\delta=0.4,0.6$, and 0.8 , the maximum roof displacement increases by approximately $1.46-31.56 \%, 5.14-66.18 \%$, and $10.93-72.23 \%$, respectively. The maximum ISDR increases by $2.99-51.47 \%, 7.32-67.01 \%$, and $15.58-76.23 \%$, respectively. Under the same earthquake sequence, with increasing $\delta$, the maximum roof displacement and the maximum ISDR of the structure gradually increases. In summary, when the PGA of the selected ground motion is relatively small, the amplitudes of the foreshock and mainshock in the earthquake sequence are very small. After the foreshock, the structure is in an elastic state. After the mainshock, which has a slightly greater intensity than the foreshock, the structure is still in an elastic state. At this time, as the damaged structure experiences the aftershock, the risk of damage to structural members can greatly increase. When the PGA of the selected ground motion is relatively large, two situations may occur. In the first situation, $\delta$ is relatively small, and the amplitude of the foreshock is relatively small, while the magnitude of the mainshock is relatively large in the earthquake sequence. After the foreshock, the structure is still in an elastic state, but, after the mainshock, the structure enters a nonlinear state, which results in structural plastic damage. In the second situation, $\delta$ is relatively large, and the peak amplitudes of both the foreshock and the mainshock in the earthquake sequence are large. As a result, the structure has already undergone moderate or severe damage during the foreshock, which exhibits notable plastic characteristics and stiffness degradation. When subjected to the mainshock with a higher intensity, the structural cumulative damage increases significantly, and the stiffness further decreases. At this time, the damaged structure experiences a strong aftershock, and the risk of collapse to the structure greatly increases. 


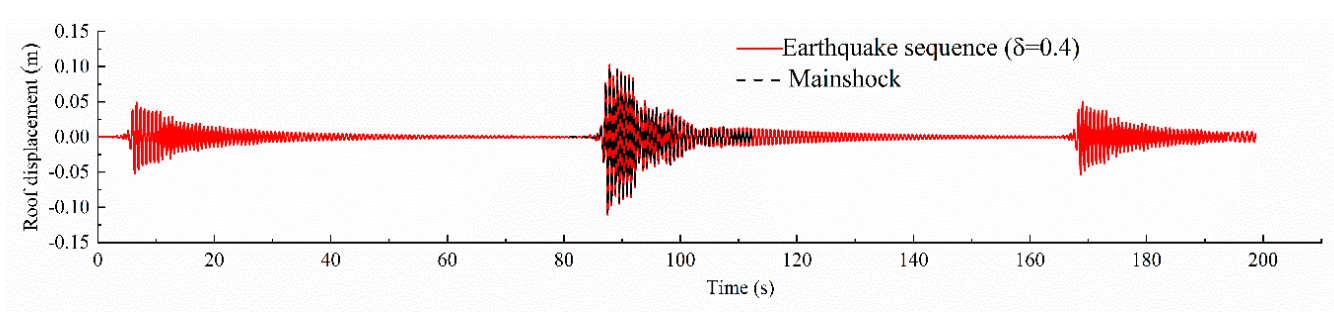

(a) $\delta=0.4$

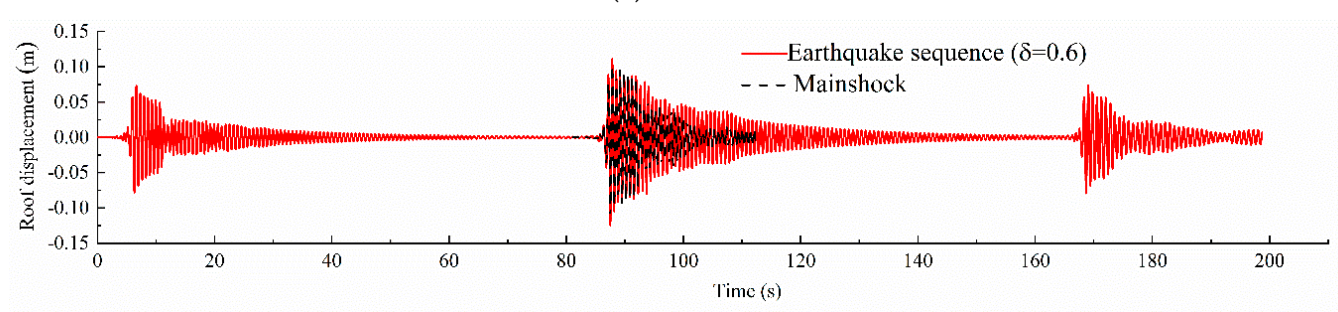

(b) $\delta=0.6$

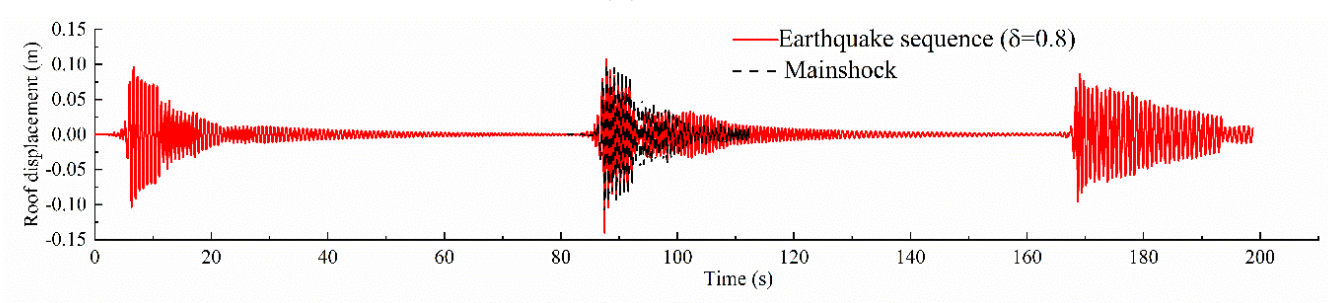

(c) $\delta=0.8$

Figure 12. Comparison of the roof displacement of CFST-B under A-CAS input motion.

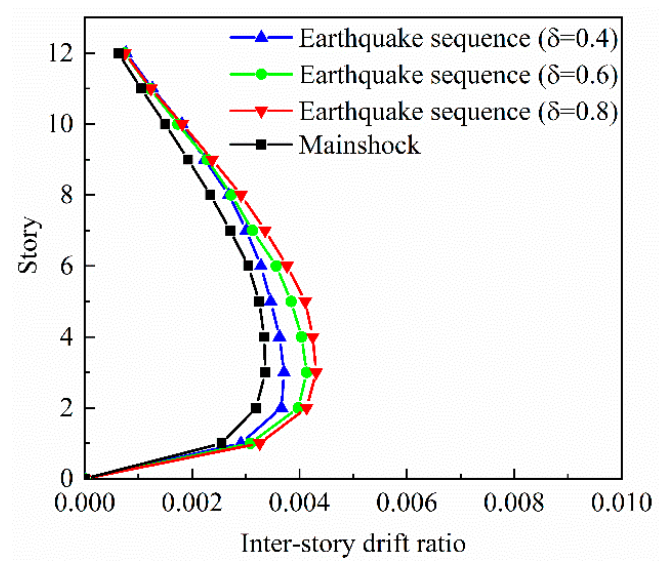

Figure 13. Comparison of the ISDRs of CFST-B under A-CAS input motion.

\section{Fragility Analysis of CFST with BRBs under Earthquake Sequences}

Seismic fragility refers to the possibility of different damage states in an engineering structure under different seismic intensities. Through seismic fragility analysis, the probability for a structure to reach or exceed a certain damage state under different seismic intensities is evaluated, which quantitatively describes the relationship between the intensity of the input ground motion and the degree of structural damage. The seismic fragility curve intuitively describes the seismic performance of the structure in terms of probability and describes the ground motion intensity and degree of structural damage in the form of a probability curve. In this section, using CFST-B as a research object and the foreshock-mainshock-aftershock sequence as the ground motion input, the seismic fragility of the CFST-B under earthquake sequences is analyzed based on the PSDA method. 


\subsection{Probabilistic Seismic Demand Model (PSDM)}

The core of establishing PSDM is to develop a relationship between the seismic response and ground motion intensity based on nonlinear time history analysis. There are two main types of methods known as the IDA method and the cloud method. In this study, the cloud method is used to statistically analyze the results of the dynamic response of the structural underground motions and present the processed data in a cloud shape in the coordinate system. The cloud method usually assumes that the seismic demand and the ground motion intensity satisfy a logarithmic linear regression relationship. Compared with the IDA method, which requires scaling, the cloud method has high computational efficiency. In the present study, the employed ground motion inputs were selected considering the earthquake magnitudes and epicentral distances using the bin approach. The five ground motion bins developed by Mackie and Stojadinović [53] are applied, including (1) small magnitude and small distance (SMSR, $5.8<\mathrm{Mw}<6.5,13<\mathrm{R}<30 \mathrm{~km}$ ), (2) large magnitude and small distance (LMSR, $6.5<$ $\mathrm{Mw}<7.0,13<\mathrm{R}<30 \mathrm{~km}$ ), (3) small magnitude and large distance (SMLR, $5.8<\mathrm{Mw}<6.5,30<\mathrm{R}<60$ $\mathrm{km}$ ), (4) large magnitude and large distance (LMLR, $6.5<\mathrm{Mw}<7.0,30<\mathrm{R}<60 \mathrm{~km}$ ), and (5) near-fault ground motions (NF, $\mathrm{R}<13 \mathrm{~km}$ ). In total, 80 ground motions (16 in each bin) are employed to take into account the ground motion randomness in assessing the seismic fragility.

Cornell et al. [54] indicated that the structural seismic demand $\left(\mu_{D}\right)$ and ground motion intensity measure (IM) satisfy the following logarithmic linear relationship.

$$
\ln \left(\mu_{D}\right)=\ln a+b \ln (I M)
$$

where $a$ and $b$ are coefficients that can be obtained by linear regression analysis based on the analysis results of the cloud method.

The PSDM of CFST-B is calculated using the above-described cloud method. Figure 14 shows the PSDM of the structure subjected to a single mainshock and different earthquake sequences with $\delta=0.4$, 0.6, and 0.8. The details of regression results for each case are shown in Table 5. As shown in Figure 14, the seismic demand parameter (ISDR $\max$ ) and the ground motion intensity parameter (PGA) follow a logarithmic linear relationship well, with coefficients of determination $R^{2}$ of $0.76618,0.75449,0.77191$, and 0.76804 , respectively. All $\mathrm{R}^{2}$ values obtained based on the results of the nonlinear time history analysis of CFST-B are greater than 0.75 , which indicates that the PSDM is highly credible in describing the probabilistic characteristics of the seismic demand of the structure. This lays a foundation for the subsequent seismic fragility analysis based on the PSDM.

Table 5. Regression parameters for the PSDMs.

\begin{tabular}{cccc}
\hline Cases & Linear Regression Model & $\mathbf{R}^{\mathbf{2}}$ & $\sigma_{D \mid I M}$ \\
\hline Mainshock & $\ln ($ ISDRx $)=-4.1604+0.96596 \ln ($ PGA $)$ & 0.76618 & 0.27845 \\
ES $(\delta=0.4)$ & $\ln ($ ISDRax $)=-4.03073+0.98723 \ln ($ PGA $)$ & 0.75449 & 0.28215 \\
ES $(\delta=0.6)$ & $\ln ($ ISDRax $)=-3.86207+1.01474 \ln ($ PGA $)$ & 0.77191 & 0.29486 \\
ES $(\delta=0.8)$ & $\ln ($ ISDRax $)=-3.79405+1.03846 \ln ($ PGA $)$ & 0.76804 & 0.31308 \\
\hline
\end{tabular}




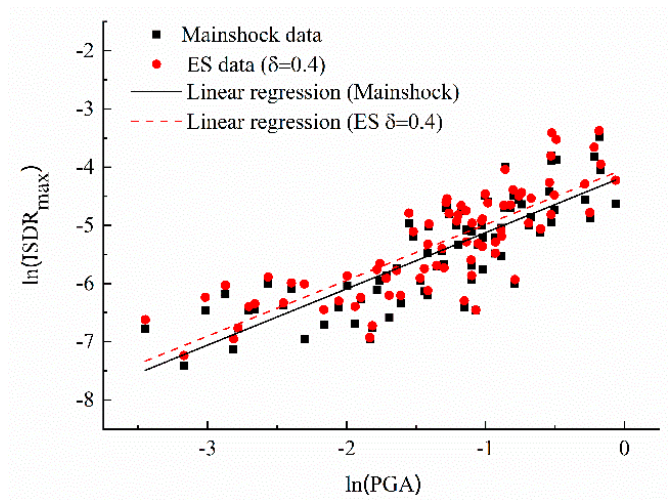

(a) Main shock and earthquake sequence $(\delta=0.4)$

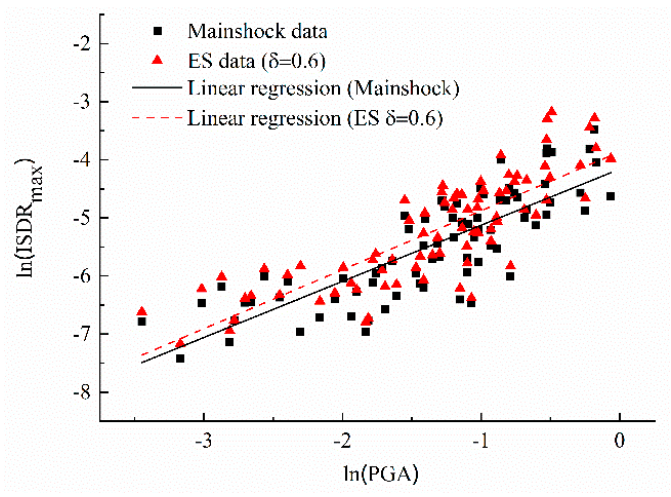

(b) Main shock and earthquake sequence $(\delta=0.6)$.

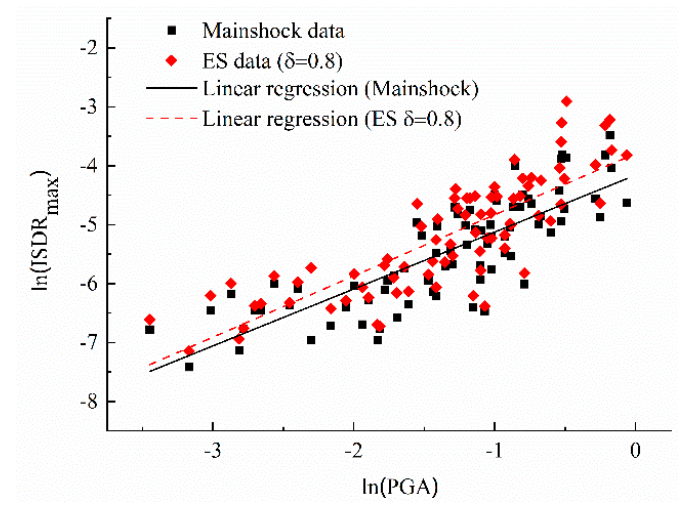

(c) Main shock and earthquake sequence $(\delta=0.8)$.

Figure 14. PSDM under main shock and earthquake sequences.

\subsection{Results and Analysis}

Assuming that the structural seismic demand follows a logarithmic linear distribution at different IMs, the seismic fragility function of a structure can be expressed by the equation below.

$$
P(D \geq C \mid I M)=\Phi\left[\frac{\ln \left(\mu_{D}\right)-\ln \left(\mu_{C}\right)}{\sqrt{\sigma_{D \mid I M}^{2}+\sigma_{C}^{2}}}\right]
$$

where $D$ and $C$ are the seismic demand and structural capacity, respectively. $\mu_{D}$ and $\mu_{C}$ are the median values of $D$ and $C$. $\sigma_{D \mid I M}$ and $\sigma_{C}$ are the corresponding standard deviations.

In this study, four structural damage limit states, known as slight damage, moderate damage, severe damage, and collapse, are considered. The division of structural damage states and the definition of the structural limit states used in this study are consistent with those specified in the Chinese Code for Seismic Design of Buildings [55]. Currently, because the CFST frame structure with BRBs is a new type of high-performance structural system, the deformation limits that characterize the seismic capacity of this structure have not been clearly specified in the code. To determine the damage limit states of CFST structures, reference is made to the "Specification for Design of Steel-Concrete Mixed Structure of Tall Buildings" [56], which recommends damage limit values for mixed frame structures under earthquakes. As a result, ISDRs of 1/400, 1/200, 1/100, and 1/50 corresponding to four damage limit states, known as slight damage (LS-1), moderate damage (LS-2), severe damage (LS-3), and collapse (LS-4), are employed to derive the seismic fragility curves herein.

Figure 15 shows the fragility curves for the damage limit states LS-1, LS-2, LS-3, and LS-4. It can be observed that all seismic fragility curves under the earthquake sequence are located above those under the single mainshock, which indicates that all damage probabilities of different damage limit states for 
the structures under earthquake sequences increased. An increasing $\delta$, which means higher impact of the earthquake sequence on the cumulative structural damage, leads to a higher damage probability.

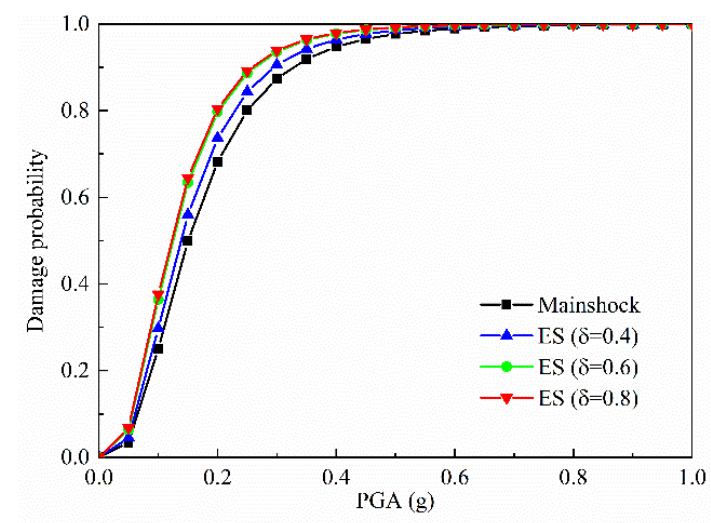

(a) LS-1

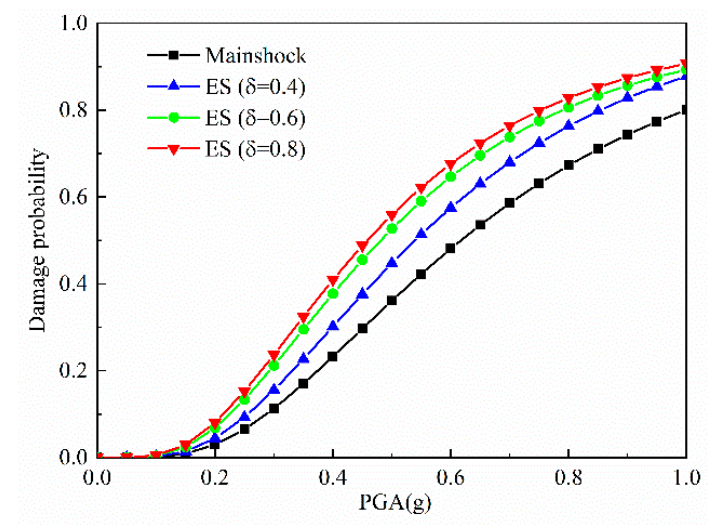

(c) LS-3

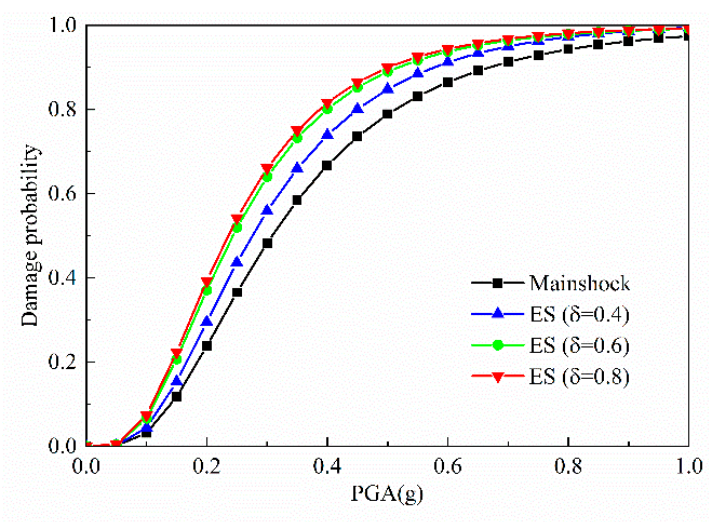

(b) LS-2

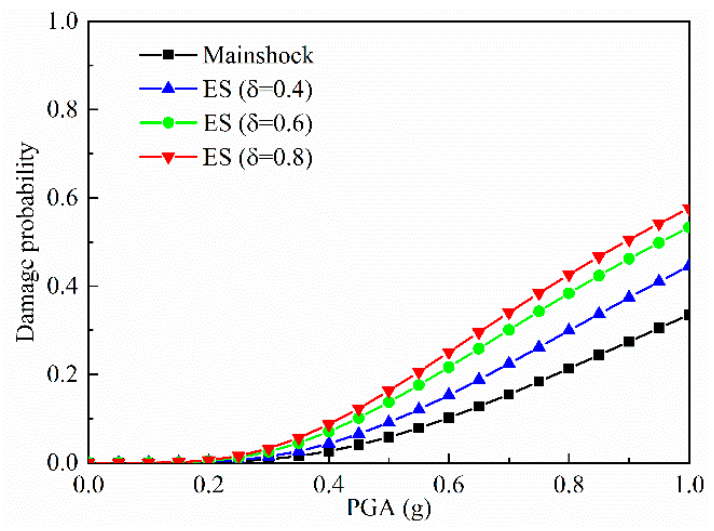

(d) LS-4

Figure 15. Fragility curves for different damage limit states.

The PGA corresponding to an exceedance probability of $50 \%$ in the seismic fragility curve is defined as the median PGA of the seismic fragility curve. The median PGAs corresponding to the structure exceeding LS- 1 under earthquake sequences with $\delta=0.4,0.6$, and 0.8 decrease by $5 \%, 7 \%$, and $12 \%$, respectively, when compared with those under the mainshock. The median PGAs corresponding to the structure exceeding LS-2 under earthquake sequences with $\delta=0.4,0.6$, and 0.8 decrease by $9 \%, 11 \%$, and $16 \%$, respectively, when compared with those under the mainshock. The median PGAs corresponding to the structure exceeding LS-3 under earthquake sequences with $\delta=0.4,0.6$, and 0.8 decrease by $14 \%, 16 \%$, and $19 \%$, respectively, when compared with those under the mainshock. The median PGAs corresponding to the structure exceeding LS-4 under earthquake sequences with $\delta=0.4,0.6$, and 0.8 decrease by $15 \%, 25 \%$, and $29 \%$, respectively, when compared with those under the mainshock. These results show that the PGA corresponding to the structure exceeding each limit state under the earthquake sequence decreases when compared with that under the mainshock. Therefore, the structure is more likely to be damaged under an earthquake sequence than under a single mainshock when the other conditions remain the same. Therefore, earthquake sequences should be considered in the seismic design of structures.

\section{Conclusions}

Using FE numerical simulation, the influences of the strain rate effect and earthquake sequence on the seismic responses and fragilities of a CFST frame structure with BRBs are systematically investigated in this paper. The following conclusions are drawn. 
(1) The strain rate can impact the structural response to a certain extent. After considering the strain rate effect of the material, the roof displacement and the ISDRs of the structure decrease.

(2) Compared with the CFST structure without BRBs, the maximum roof displacement and ISDR of the CFST structure with BRBs decrease by $45.1 \%$ and $43.9 \%$, respectively. Therefore, BRBs can effectively improve the seismic capacity of the CFST frame structure.

(3) Compared with those under single mainshocks, the maximum roof displacement and the ISDR of the CFST structure with BRBs under earthquake sequences significantly increase. Under an earthquake sequence with $\delta=0.8$, the maximum roof displacement and the maximum ISDR of the structure increase by $72.23 \%$ and $76.23 \%$, respectively. Moreover, with an increasing scaling coefficient, the seismic response significantly increases.

(4) The median PGA corresponding to the structure exceeding each damage limit state under an earthquake sequence decreases when compared with that under a mainshock. The fragility of the CFST structure with BRBs under an earthquake sequence is significantly greater than that under a single mainshock. Therefore, earthquake sequences should be considered in the seismic design of CFST structures. The probabilities of the structure exceeding each limit state increase with rising $\delta$ of the earthquake sequence. The extent of the increase is more significant for severe damage and collapse limit states.

Author Contributions: Conceptualization, H.Z. and C.L. Methodology, H.Z. and C.L. Software, S.-M.J. Formal analysis, P.-F.L. Data curation, Q.-M.G. Writing—original draft preparation, S.-M.J. and P.-F.L. Writing-review and editing, H.Z. and C.L. Project administration, H.Z. Funding acquisition, H.Z. and C.L. All authors have read and agreed to the published version of the manuscript.

Funding: This research was funded by the National Key R\&D Program of China (Grant No. 2018YFD1100404, 2016YFC0701108), the State Key Program of the National Natural Science Foundation of China (Grant No. 51738007), the Program of Guangdong Key Laboratory of Earthquake Engineering and Application Technology (Grant No. 2017B030314068), the Natural Science Foundation of Liaoning Province (Grant No. 20180550949), and the Project funded by China Postdoctoral Science Foundation (Grant No. 2018M640253).

Acknowledgments: The authors are grateful for the financial support from the National Key R\&D Program of China (2018YFD1100404, 2016YFC0701108) and the State Key Program of the National Natural Science Foundation of China (51738007) for carrying out this research. The support from the Program of Guangdong Key Laboratory of Earthquake Engineering and Application Technology (2017B030314068) and the Natural Science Foundation of Liaoning Province (20180550949) is also gratefully acknowledged. The second author also thanks the financial support from the project funded by China Postdoctoral Science Foundation (2018M640253).

Conflicts of Interest: The authors declare no conflict of interest.

\section{References}

1. Bai, Y.; Wang, J.; Liu, Y. Thin-walled CFST columns for enhancing seismic collapse performance of high-rise steel frames. Appl. Sci. 2017, 7, 53. [CrossRef]

2. Zhang, J.; Li, Y.; Zheng, Y. Seismic damage investigation of spatial frames with steel beams connected to L-shaped concrete-filled steel tubular (CFST) columns. Appl. Sci. 2018, 8, 1713. [CrossRef]

3. Jia, S.Z.; Cao, W.L.; Liu, Z.B. Experimental study on a prefabricated lightweight concrete-filled steel tubular framework composite slab structure subjected to reversed cyclic loading. Appl. Sci. 2019, 9, 1264.

4. Sabelli, R.; Mahin, S.; Chang, C. Seismic demands on steel braced frame buildings with buckling-restrained braces. Eng. Struct. 2003, 25, 655-666. [CrossRef]

5. Fahnestock, L.A.; Sause, R.; Ricles, J.M. Seismic response and performance of buckling-restrained braced frames. J. Struct. Eng. 2007, 133, 1195-1204. [CrossRef]

6. Ren, F.; Zhou, Y.; Chen, G. Experimental study on seismic performance of concrete-filled steel tabular frame-shear wall structure with buckling-resistant braces. Struct. Des. Tall Spec. 2015, 24, 73-95. [CrossRef]

7. Wu, Y.; Song, W.; Zhao, W. An experimental study on dynamic mechanical properties of fiber-reinforced concrete under different strain rates. Appl. Sci. 2018, 8, 1904. [CrossRef]

8. Atchley, B.L.; Furr, H.L. Strength and energy absorption capabilities of plain concrete under dynamic and static loadings. Am. Inst. Phys. Conf. Ser. 1967, 378, 268-274.

9. Chang, K.C.; Lee, G.C. Strain rate effect on structural steel under cyclic loading. J. Eng. Mech. 1987, 113, 1292-1301. [CrossRef] 
10. Wakabayshi, M. Dynamic Loading Effects on the Structural Performance of Concrete and Steel Materials and Beams. In Proceedings of the Seventh World Conference on Earthquake Engineering, Istanbul, Turkey, 8-13 September 1980; Volume 6, pp. 271-278.

11. Filiatrault, A.; Holleran, M. Stress-strain behavior of reinforcing steel and concrete under seismic strain rates and low temperatures. Mater. Struct. 2001, 34, 235-239. [CrossRef]

12. Fu, H.C.; Erki, M.A.; Seckin, M. Review of effects of loading rate on reinforced concrete. J. Struct. Eng. 1991, 117, 3660-3679. [CrossRef]

13. Malvar, L.J.; Ross, C.A. Review of strain rate effects for concrete in tension. ACI Mater. J. 1998, 95, 435-439.

14. Bischoff, P.H.; Perry, S.H. Compressive behaviour of concrete at high strain rates. Mater. Struct. 1991, 24, 425-450. [CrossRef]

15. Bertero, V.V.; Rea, D.; Mahin, S.A. Rate of Loading Effects on Uncracked and Repaired Reinforced Concrete Members. In Proceedings of the Fifth World Conference on Earthquake Engineering, Rome, Italy, 25-29 June 1973; Volume 1, pp. 1461-1470.

16. Li, M.; Li, H. Effects of strain rate on reinforced concrete structure under seismic loading. Adv. Struct. Eng. 2012, 15, 461-475. [CrossRef]

17. Li, H.N.; Li, M. Experimental and numerical study on dynamic properties of RC beam. Mag. Concr. Res. 2013, 65, 744-756. [CrossRef]

18. Wang, D.; Li, H.N.; Li, G. Experimental tests on reinforced concrete columns under multi-dimensional dynamic loadings. Const. Build. Mater. 2013, 47, 1167-1181. [CrossRef]

19. Carrillo, J.; Alcocer, S.M. Experimental investigation on dynamic and quas-static behavior of low-rise reinforced concrete walls. Earthq. Eng. Struct. Dyn. 2013, 42, 635-652. [CrossRef]

20. Asprone, D.; Frascadore, R.; Ludovico, M.D. Influence of strain rate on the seismic response of RC structure. Eng. Struct. 2012, 35, 29-36. [CrossRef]

21. Zhang, H.; Li, H.N.; Li, C.; Cao, G.W. Experimental and numerical investigations on seismic responses of reinforced concrete structures considering strain rate effect. Const. Build. Mater. 2018, 173, 672-686. [CrossRef]

22. Luco, N.; Bazzurro, P.; Cornell, C.A. Dynamic Versus Static Computation of the Residual Capacity of a Mainshock-Damaged Building to Withstand an Aftershock. In Proceedings of the 13th World Conference on Earthquake Engineering, Auckland, New Zealand, 1-6 August 2004.

23. Sarno, L.D. Effects of multiple earthquakes on inelastic structural response. Eng. Struct. 2013, 56, 673-681. [CrossRef]

24. Ruiz-García, J.; Aguilar, J.D. Influence of modeling assumptions and aftershock hazard level in the seismic response of post-mainshock steel framed buildings. Eng. Struct. 2017, 140, 437-446. [CrossRef]

25. Fragiacomo, M.; Amadio, C.; Macorini, L. Seismic response of steel frames under repeated earthquake ground motions. Eng. Struct. 2004, 26, 2021-2035. [CrossRef]

26. Duerr, K. Seismic Vulnerability Assessment and Retrofit Optimization of Non-Code Conforming Buildings with Consideration of Mainshock-Aftershock Earthquake. Master's Thesis, The University of British Columbia, Vancouver, BC, Canada, 2014.

27. Goda, K.; Salami, M.R. Inelastic seismic demand estimation of wood-frame houses subjected to mainshock-aftershock sequences. Bull. Earthq. Eng. 2014, 12, 855-874. [CrossRef]

28. Han, R.; Li, Y.; Lindt, J.V.D. Impact of aftershocks and uncertainties on the seismic evaluation of non-ductile reinforced concrete frame buildings. Eng. Struct. 2015, 100, 149-163. [CrossRef]

29. Song, R.; Li, Y.; Van, D.L.J.W. Loss estimation of steel buildings to earthquake mainshock-aftershock sequences. Struct. Saf. 2016, 61, 1-11. [CrossRef]

30. Ellingwood, B.R. Earthquake risk assessment of building structures. Reliab. Eng. Syst. Saf. 2001, 74, $251-262$. [CrossRef]

31. Sasani, M.; Kiureghian, A.D. Seismic fragility of RC structural walls: Displacement approach. J. Struct. Eng. 2001, 127, 219-228. [CrossRef]

32. Ryu, H.; Luco, N.; Uma, S.; Liel, A. Developing Fragilities for Mainshock-Damaged Structures through Incremental Dynamic Analysis. In Proceedings of the 9th Pacific Conference on Earthquake Engineering, Auckland, New Zealand, 14-16 April 2011.

33. Gardoni, P.; Kiureghian, A.; Mosalam, K.M. Probabilistic capacity models and fragility estimates for reinforced concrete columns based on experimental observations. J. Eng. Mech. 2002, 128, 1024-1038. [CrossRef]

34. Li, C.; Hao, H.; Li, H. Seismic fragility analysis of reinforced concrete bridges with chloride induced corrosion subjected to spatially varying ground motions. Int. J. Struct. Stab. Dyn. 2016, 16, 1550010. [CrossRef] 
35. Li, C.; Li, H.N.; Hao, H. Seismic fragility analyses of sea-crossing cable-stayed bridges subjected to multi-support ground motions on offshore sites. Eng. Struct. 2018, 165, 441-456. [CrossRef]

36. Li, Q.; Ellingwood, B.R. Performance evaluation and damage assessment of steel frame buildings under main shock-aftershock earthquake sequences. Earthq. Eng. Struct. Dyn. 2010, 36, 405-427. [CrossRef]

37. Abdelnaby, A.E.; Elnashai, A.S. Performance of degrading reinforced concrete frame systems under the Tohoku and Christchurch earthquake sequences. J. Earthq. Eng. 2014, 18, 1009-1036. [CrossRef]

38. Jeon, J.S.; DesRoches, R.; Lowes, L.N. Framework of aftershock fragility assessment-case studies: Older California reinforced concrete building frames. Earthq. Eng. Struct. Dyn. 2015, 44, 2617-2636. [CrossRef]

39. Li, Y.; Song, R.; Van De, L.J.W. Collapse fragility of steel structures subjected to earthquake mainshock-aftershock sequences. J. Struct. Eng. 2014, 140, 04014095. [CrossRef]

40. National Standards of the People's Republic of China. Code for Design of Concrete Structures; GB 50010-2010; Standards Press of China: Beijing, China, 2010.

41. Clough, R.W.; Johnson, S.B. Effect of stiffness degradation on earthquake ductility requirements. In Proceedings of the Japan Earthquake Engineering Symposium, Tokyo, Japan, October 1966; pp. 195-198. Available online: https://link.springer.com/article/10.1007/s11803-006-0631-0 (accessed on 24 November 2019).

42. Han, L.H. Theory and Practice of Concrete Filled Steel Tubular Structure, 3rd ed.; Science Press: Beijing, China, 2007; pp. 170-186.

43. Zhang, X.H.; Duan, Z.D.; Zhang, C.W. Numerical simulation of dynamic response for steel frame structures subjected to blast load. Trans. Tianjin Univ. 2008, 14, 523-529. [CrossRef]

44. Gholipour, G.; Zhang, C.W.; Mousavi, A. Effects of axial load on nonlinear response of RC columns subjected to lateral impact load: Ship-pier collision. Eng. Fail. Anal. 2018, 91, 397-418. [CrossRef]

45. Zhang, C.W.; Gholipour, G.; Mousavi, A.A. Nonlinear dynamic behavior of simply-supported RC beams subjected to combined impact-blast loading. Eng. Struct. 2019, 181, 124-142. [CrossRef]

46. Xiao, S.; Li, H.; Monteiro, P.J.M. Influence of strain rates and loading histories on the compressive damage behaviour of concrete. Mag. Concr. Res. 2011, 63, 915-926. [CrossRef]

47. Zhang, H.; Li, H.N.; Cao, G.W. Fiber beam element model for reinforced concrete structures considering strain rate effects. J. Build. Struct. 2019, 40, 103-112.

48. Yan, D.M.; Lin, G. Dynamic properties of concrete in direct tension. Cem. Concr. Res. 2006, 36, 1371-1378. [CrossRef]

49. Hao, X.Y.; Li, H.N.; Li, G. Experimental investigation of steel structure with innovative H-type steel unbuckling braces. Struct. Des. Tall Spec. 2014, 23, 1064-1082. [CrossRef]

50. Charney, F.A.; Marshall, J. A Comparison of the Krawinkler and scissors models for including beam-column joint deformations in the analysis of moment-resisting steel frames. Eng. J. AISC 2006, 43, 31-48.

51. Gutenberg, B.; Richter, C.F. Seismicity of the Earth and Associated Phenomena, 2nd ed.; Princeton University Press: Princeton, NJ, USA, 2013; pp. 236-244.

52. Hatzigeorgiou, G.D.; Beskos, D.E. Inelastic displacement ratios for SDOF structures subjected to repeated earthquakes. Eng. Struct. 2009, 31, 2744-2755. [CrossRef]

53. Mackie, K.; Stojadinović, B. Fragility Basis for California Highway Overpass Bridge Seismic Decision Making; PEER Report No. 2005/02; Pacific Earthquake Engineering Research Center, University of California: Berkeley, CA, USA, 2005.

54. Cornell, C.A. The probabilistic basis for the 2000SAC/FEMA steel moment frame guidelines. J. Struct. Eng. 2002, 128, 526-533. [CrossRef]

55. National Standards of the People's Republic of China. Code for Seismic Design of Buildings; GB 50011-2010; Standards Press of China: Beijing, China, 2010.

56. China Association for Engineering Construction Standardization. Code for Design of Steel-Concrete Hybrid Structures for High-Rise Building; CECS 230:2008; China Association for Engineering Construction Standardization: Beijing, China, 2008.

(C) 2019 by the authors. Licensee MDPI, Basel, Switzerland. This article is an open access article distributed under the terms and conditions of the Creative Commons Attribution (CC BY) license (http://creativecommons.org/licenses/by/4.0/). 